Blockchain Research, Practice and Policy: Applications, Benefits, Limitations, Emerging Research Themes and Research Agenda

\author{
Laurie Hughes \\ Emerging Markets Research Centre (EMaRC) \\ School of Management \\ Swansea University, UK \\ Email: d.1.hughes@swansea.ac.uk \\ Yogesh K. Dwivedi \\ Emerging Markets Research Centre (EMaRC) \\ School of Management \\ Swansea University, UK \\ Email: y.k.dwivedi@swansea.ac.uk \\ Santosh K Misra, IAS \\ CEO, Tamil Nadu e-Governance Agency \\ Commissioner of e-Governance \\ Govt of Tamil Nadu, India \\ Email: santoshmisraias@gmail.com \\ Nriprenda Rana \\ merging Markets Research Centre (EMaRC) \\ School of Management \\ Swansea University, UK \\ Email: nrananp@gmail.com \\ Vishnupriya Raghavan \\ Manipal Global Education Services \\ Bangalore, India \\ Email: vishnupriyaraghavan@gmail.com \\ Viswanadh Akella \\ SimpliFI \\ Bangalore, India \\ Email: viswanadh@simplyfi.tech
}




\title{
Blockchain Research, Practice and Policy: Applications, Benefits, Limitations, Emerging Research Themes and Research Agenda
}

\begin{abstract}
The blockchain has received significant attention from technology focussed researchers, highlighting its perceived impact and emerging disruption potential, but has been slow to engender any significant momentum within the Information Systems (IS) and Information Management (IM) literature. This study approaches the subject through an IS/IM lens developing the key themes from the blockchain based research via a comprehensive review. This analysis of the body of literature highlights that although few commercial grade blockchain applications currently exist, the technology demonstrates significant potential to benefit a number of industry wide use cases. This study expands on this point articulating through each of the key themes to develop a detailed narrative on the numerous potential blockchain applications and future direction of the technology, whilst discussing the many barriers to adoption. The study asserts that blockchain technology has the potential to contribute to a number of the UN Sustainability Development Goals and engender widespread change within a number of established industries and practices.
\end{abstract}

Keywords: Barriers; Blockchain; Information Systems; Literature Review; Opportunities; Sustainable Development Goals (UNSDGs)

\section{Introduction}

Organisations are demonstrating increasing interest in blockchain technology due to the promise of significant business benefits. Blockchain can facilitate increased levels of disintermediation where suppliers can transact directly with customers, negate the need for reconciliations, efficiently track assets and assure the integrity of data (Lacity 2018). The concept of the blockchain and its associated cryptocurrencies such as Bitcoin, Litecoin, and Ethereum, have attracted significant attention in recent years within academia and practice. Blockchain is positioned as a key emerging technological trend with studies highlighting its potential market disruption in supporting authenticated and trusted decentralised secure transactions (Ølnes et al. 2017; Yli-Huumo et al. 2016). Studies have analysed the blockchain literature, highlighting a number of innovative applications in areas such as: secure contracts, creation of e-health records, finance and supply chain management (Beck et al. 2017). The planned 2019 launch of tZero - the first SEC-cleared digital security token that is positioned to ultimately reshape global equity and financial markets, highlights the corporate confidence in the potential of this technology (IBD 2018).

The migration toward blockchain technology is influenced by a number of factors including regional and cultural considerations, that could engender greater momentum to solve specific problems and directly benefit citizens. This is especially so for emerging economies such as India where a number of leading banks including: Standard Chartered, Mumbai ICICI, HDFC, Kotak Mahindra, and Axis bank are among a consortium of 11 big lenders set to launch the country's first blockchain-linked funding for Small and Medium Enterprises (SMEs). The consortium is hoping a new industry-wide blockchainbased solution will deliver a number of benefits including: cutting timeframes in supply-chain financing, reduced costs, deepen credit catchment area and increase the number of SMEs integrated into the formal credit system. It is expected that this new initiative will make lending more transparent and less susceptible to fraud (Economic Times 2019).

Blockchain can be viewed as a distributed peer to peer ledger comprising of an ordered set of connected and replicated blocks of data. At its core, integrity of the blockchain is maintained via the use of public key encryption for any interaction or changes to the network (Dresher 2017). From an 
architecture and structural perspective, the configuration of the blockchain is structured around a distributed database, decentralized immutable consensus mechanism, secured via cryptographic algorithms that control each block in the chain (Bailis et al. 2017; Hawlitschek et al. 2018).

Although blockchain technology and cryptocurrencies in general have received considerable coverage within the last few years, studies have highlighted that transformative applications are still not commercially available and few organisations have progressed their blockchain solutions beyond the feasibility or prototype stage (Axios 2018; Iansiti and Lakhani 2017). Aligning an organisations strategy to a blockchain solution with known challenges in the areas of performance, scalability and integration with other systems, is no easy task when the realisation of benefits is uncertain. Additionally, there are cultural, regulatory, legal and logistical issues that are yet to be solved to clear the path for greater uptake of the technology. Given these challenges, it is not surprising that few organisations are prepared to commit significant investment beyond the prototype stage to bridge the gap between promised and actual business value (Lacity 2018). However, despite these uncertainties, the inherent characteristics of blockchain make the technology an attractive prospect for many organisations. Furthermore, it is clear that significant momentum is currently driving blockchain, where the numerous potential applications and perceived benefits of the technology are generating significant interest at a global level.

Studies have generally tended to focus on the technical and performance aspects of blockchain concentrating on themes such as security, performance and privacy in the context of cryptocurrencies and their potential disruption to existing processes (Dorri et al. 2017; Li \& Wang 2017; Wüst and Gervais 2018). The lack of a wider debate on this topic has been acknowledged in specific areas of the literature, where searches have revealed that over 80 percent of studies have focused on the technological aspects of blockchain with less than 20 percent discussing blockchain applications and the business focussed challenges (Yli-Huumo et al. 2016). However, a more business and IS themed debate seems to be emerging within the literature, where studies tend to look beyond the technical nuances of blockchain and concentrate on realistic applications, limitations of the technology and overall business benefits to the organisation (Kuo et al. 2017; Ølnes et al. 2017).

Review studies focussing on blockchain technology and its application have featured within the literature. The study by Hawlitschek et al. (2018) analyses blockchain and its key attributes focussing primarily on the critical aspect of trust within the sharing economy. The review undertaken by Grover et al. (2018) explored a number of use cases within Business to Government, Business to Business and Business to Consumer contexts, highlighting the wide potential for the technology and its application. This study extends many of the key elements from these previous review studies, offering a wider analysis and narrative where we isolate a number of key themes surrounding blockchain. The study analyses the benefits and limitations, discuss key cases where blockchain can address real world problems, analyse blockchain in the context of United Nations (UN) Sustainable Development Goals (SDG) and develop a number of propositions aligned to a newly presented framework to guide future research on this important topic.

The subsequent sections of this study are as follows: Section 2 describes how the blockchain technology works in practice, discussing the network architecture and transaction mechanism; Section 3 discusses the literature review where the method and key themes are outlined; Section 4 provides an industrial focussed perspective on blockchain; section 5 discusses two specific cases based on migrant families and low paid farmers in India where blockchain technology could be used to deliver key benefits to families living below the poverty line; section 6 pulls together the key elements of the study and discusses blockchain the context of the UN SDGs. This section also details the key propositions of the study and outlines a number of potential future research directions and the final section details the concluding points of the study. 


\section{How the blockchain works}

The concept of the blockchain was first proposed by Nakamoto (2008) in the context of a peer to peer electronic cash system titled - Bitcoin. This initial study discussed the potential of a new peer-to-peer technology operating with no central authority or bank where collectively the network manages the transactions and the issuing of bitcoins. At its core, the concept proposed by Nakamoto relied on a multi-signature feature to authorise all transactions thereby, ensuring consent from other members and a full audit trail identifying which members permitted each particular transaction (Nakamoto 2008). These initial concepts and ideas relating to Bitcoin have matured to encompass a wider field of economic and commercial applications where the management and processing of cryptocurrencies is just one application of the technology (Dresher 2017; Hawlitschek et al. 2018). Figure 1 highlights the structural variance between a traditional ledger based system architecture and the blockchain architecture. The traditional structure consists of a number of ledgers or databases directly connected to a central or trusted $3^{\text {rd }}$ party ledger. In this configuration each node in the network maintains their own ledger but also relies on the central ledger as the master record. The blockchain structure does not require the use of the trusted central ledger, as each node in the network holds its own identical ledger copy that transacts directly with all other nodes in the network. The net effect of this configuration is that at any point in time all ledgers are synchronised across the network and transact directly without the need for the trusted $3^{\text {rd }}$ party node (Hawlitschek et al. 2018; Lacity 2018).
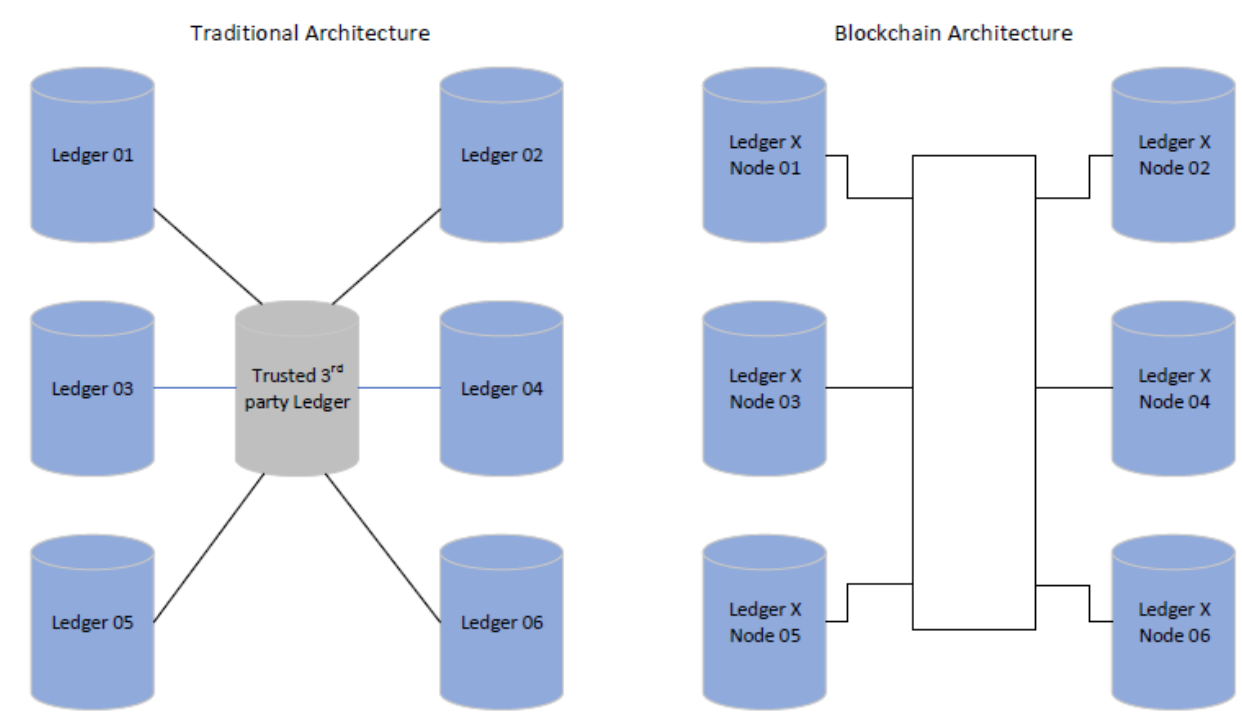

Figure 1: Traditional vs blockchain architecture (Source: Adapted from Lacity 2018; Ølnes et al. 2017).

The research by lansit and Lakhani (2017) identified a number of basic principles that underpin the workings of blockchain technology, highlighting the key differences when compared to a traditional architecture:

1. Distributed ledger or database: Each block in the chain has access to the entire database and the full audit trail of all transactions. The data stored within each ledger is not controlled by any single party. Each node can verify the records of all transactions across the network without needing a central node or trusted $3^{\text {rd }}$ party.

2. Direct node to node communication: Each node communicates with other nodes in the network where each ledger stores the data and forwards it to all other connected nodes. 
3. Accessibility within the network: Each transaction and associated data are visible to all parties within the network. Transactions occur between unique blockchain addresses.

4. Immutability: All transactions, once entered in to the ledger, cannot be changed as the data is replicated across all nodes in the network. Data stored within the blockchain is permanent, chronologically ordered and available to all nodes. This differs somewhat from the traditional model where data can be changed and re-ordered.

5. Computational logic: Transactions can be programmed to be automatically triggered between nodes via the use of secure algorithms without any control from a central node.

The challenge to the blockchain network is to ensure the system is open to all parties whilst guaranteeing only valid transactions are added (Drescher 2017). In the event that a new transaction is requesting to join the network, the request is communicated to all nodes in the blockchain. The new transaction is validated via cryptographic algorithms by all nodes within the network. Each node in the blockchain verifies that the new transaction is valid. Once approved the new transaction is added as a new block to the chain. At this stage, each ledger on every node in the network identifies the fact that the record and associated audit trail has been updated to reflect the addition of a new block in the chain (Drescher 2017; lansiti and Lakhani 2017; Lacity 2018).

Drescher (2017) highlights that blockchains are effectively a digital storage network that is totally independent of the data contained within each block and identifies the key characteristics as:

- Immutable: Once a transaction has been added to the blockchain it cannot be altered.

- Time stamped: All records are date and time stamped thereby, ensuring a built-in audit trail is maintained for all additions to the network.

- Append only: Data can only be added to the blockchain in time-ordered sequential order.

- Secure: All additions to the blockchain are governed via secure algorithms that use public key encryption, thereby, reducing the risk of data corruption or fraud.

- Open and transparent: The distributed ledger nature of the blockchains means that all nodes in the network share the same master records. These characteristics make the blockchain more accurate and consistent across the entire network.

These characteristics and inherent properties of blockchain open up a number of potential applications beyond that of cryptocurrency, where these attributes can offer advantages over traditional centralised methods. Aspects of the literature have explored the potential of blockchain leveraging the characteristics of the technology to offer a number of application areas, namely: smart contracts (Mendling et al. 2018), digital payments (Drescher 2017), supply chain management (Lacity 2018), accounting and assurance (Dai \& Vasarhelyi 2017), transport and logistics (Dobrovnik et al. 2018), peer review and voting (Avital 2018). The advantages that blockchain can bring to many of these use cases is one where one or more of the characteristics listed above, can provide direct benefits to users and contracting parties. Many studies refer to a logistics and supply chain scenario when articulating how blockchain can offer benefits over traditional based approaches (Dobrovnik et al. 2018; lansiti and Lakhani 2017; Kshetri 2017). In the supply chain context, the blockchain ledger would detail the history of the product journey from supplier to consumer and via the use of RFID and GPS technology, goods would be tracked through every stage. Trust would be guaranteed via the immutability of the technology as fraud could be easily detected within any part of the supply chain. Costs would be reduced in the supply chain context due to disintermediation, as blockchain negates the requirement for agents or intermediaries. The settlement of monies would be automated where the conditions detailed in the smart contract are fulfilled and goods are delivered to the customer. Importantly trust is engendered by all stakeholders as the integrity of the blockchain is maintained and all ledger records are visible by all parties. 


\section{Literature Review and Key Themes}

Although numerous studies relating to blockchain have been published, the literature relating to blockchain technology from the IS perspective is immature. Generally, the studies in scope tend to span from 2017 onwards with a relatively increasing number within 2018 and 2019. This section explores the literature within these periods and all relevant earlier studies.

\subsection{Literature review method}

Initial basic searches for blockchain related terms across all genres of research returned many 1000's of results. The search terms "Blockchain" or "Block chain" were used within the Scopus database to retrieve only ABS ranked publications. This specific search yielded just 33 relevant results. Each of the articles retrieved by this search were reviewed for relevance and quality. This exercise necessitated the removal of results that were not relevant and the addition of new studies via the extended literature review of this initial list of articles. The decision to include additional studies was based on a relevance assessment adopting an approach similar to other existing reviews such as Duan et al. (2019), Ismagilova et al. (2019), Kapoor et al. (2018) and Kuttimani et al. (2019). The result of this process was a list of 51 publications that were deemed to be within the scope required for this study. Each of these remaining studies were reviewed to extract the key points, contribution to the literature and research limitations. This data was tabulated and used to develop a synthesis of the topic and to develop the key themes for this study based on the content of each of the articles. Each of the listed key themes were identified based on a detailed analysis of the content and commonality between the selected studies. The final stage of this exercise was the identification of which specific studies aligned with each of the developed key themes.

\subsection{Literature review themes and references}

The alignment of relevant blockchain studies and the associated themes are presented in Table 1. Where studies have discussed areas relating to more than one of the selected themes, each instance is listed in the table. The selection of themes is based on an overall assessment of the key topics covered within each of the articles forming the literature review search results.

Table 1: Literature review results aligned to blockchain theme.

\begin{tabular}{|l|l|l|}
\hline $\begin{array}{l}\text { Blockchain } \\
\text { Theme }\end{array}$ & Theme Description & Literature References \\
\hline $\begin{array}{l}\text { Commercial } \\
\text { Rensiderations and }\end{array}$ & $\begin{array}{l}\text { Analysis of the } \\
\text { commercial } \\
\text { perspectives value } \\
\text { creation from } \\
\text { blockchain }\end{array}$ & $\begin{array}{l}\text { Axios (2018); Dobrovnik et al. (2018); Drescher (2017); } \\
\text { Forester (2018); Holub \& Johnson (2018); lansiti and Lakhani } \\
\text { (2017); Kshetri, (2018); Lacity (2018); Michelman (2017); } \\
\text { Rabah (2017); Staples et al. (2017); Ying et al. (2018); Zalan } \\
\text { (2018). }\end{array}$ \\
\hline $\begin{array}{l}\text { Security, Integrity } \\
\text { and Trust }\end{array}$ & $\begin{array}{l}\text { Security and integrity } \\
\text { implications of utilising } \\
\text { blockchain based } \\
\text { systems within } \\
\text { organisations. }\end{array}$ & $\begin{array}{l}\text { Beck et al. (2016); Böhme et al. (2017); Drescher (2017); } \\
\text { Fengi et al. (2018); Fosso Wamba (2018); Gomber et al. } \\
\text { (2018); Guo and Liang (2016); Hawlitschek et al. (2018); } \\
\text { Lacity (2018); Mendling et al. (2018); Pazaitis et al. (2017); } \\
\text { Seebacher and Schüritz (2017); Weber et al. (2016); Ying et } \\
\text { al. (2018). }\end{array}$ \\
\hline $\begin{array}{l}\text { Business Model } \\
\text { Processes } \\
\text { Implications }\end{array}$ & $\begin{array}{l}\text { Impact on business } \\
\text { models and associated } \\
\text { processes as a direct } \\
\text { result of implementing } \\
\text { blockchain based }\end{array}$ & $\begin{array}{l}\text { Dobrovnik et al. (2018); Drescher (2017); Forester (2018); } \\
\text { lansiti and Lakhani (2017); Kypriotaki et al. (2015); Mendling } \\
\text { et al. (2018); Michelman (2017); Peters and Panayi (2016); } \\
\text { Prybila et al. (2017); Tan et al. (2018); Weber et al. (2016); } \\
\text { Ying et al. (2018); Zamani \& Giaglis (2018). }\end{array}$ \\
\hline
\end{tabular}




\begin{tabular}{|c|c|c|}
\hline & systems. & \\
\hline Cost \& Performance & $\begin{array}{l}\text { Potential cost } \\
\text { implications of } \\
\text { implementing block } \\
\text { chain solutions and } \\
\text { impacts on } \\
\text { performance for the } \\
\text { transacting entities. } \\
\end{array}$ & $\begin{array}{l}\text { Alabi, K. (2017); Beck et al. (2016); Dobrovnik et al. (2018); } \\
\text { Gomber et al. (2018); Holub \& Johnson (2018); Iansiti and } \\
\text { Lakhani (2017); Mendling et al. (2018); Michelman (2017); } \\
\text { Rimba et al. (2017); Staples et al. (2017). }\end{array}$ \\
\hline $\begin{array}{l}\text { Cryptocurrencies } \\
\text { and Online } \\
\text { Transactions }\end{array}$ & $\begin{array}{l}\text { Financial transactions } \\
\text { between organisations } \\
\text { using popular } \\
\text { blockchain currencies } \\
\text { such as Bitcoin or } \\
\text { Ethereum. }\end{array}$ & $\begin{array}{l}\text { Bailis et al. (2017); Böhme et al. (2017); Eyal \& Sirer (2018); } \\
\text { Holub \& Johnson (2018); lansiti and Lakhani (2017); Li \& } \\
\text { Wang (2017); Staples et al. (2017); Tang et al. (2019); Tasca } \\
\text { et al. (2018); Zamani and Giaglis (2018). }\end{array}$ \\
\hline $\begin{array}{l}\text { Potential } \\
\text { blockchain Business } \\
\text { Applications }\end{array}$ & $\begin{array}{l}\text { Applications for } \\
\text { blockchain and } \\
\text { assessment of the } \\
\text { many and varied } \\
\text { potential blockchain } \\
\text { based systems and } \\
\text { solutions presented } \\
\text { within the literature. }\end{array}$ & $\begin{array}{l}\text { Avital (2018); Axios (2018); Bailis et al. (2017); Barnett \& } \\
\text { Treleaven (2018); Beck et al. (2016); Beck et al. (2017); } \\
\text { Carrenõ et al. (2018); Coyne \& McMickle (2017); Dai \& } \\
\text { Vasarhelyi (2017); Dobrovnik et al. (2018); Fengi et al. } \\
\text { (2018); Gomber et al. (2018); Guo and Liang (2016); lansiti } \\
\text { and Lakhani (2017); IBD (2018); Kshetri (2018); Levine } \\
\text { (2017); Li et al. (2018); Ølnes et al. (2017); Peters and Panayi } \\
\text { (2016); Queiroz and Wamba (2019); Staples et al. (2017); } \\
\text { Swan (2015); Tapscott and Tapscott (2017); White (2017). }\end{array}$ \\
\hline $\begin{array}{l}\text { Assessment of } \\
\text { Benefits and } \\
\text { Market Disruption } \\
\text { Potential }\end{array}$ & $\begin{array}{l}\text { Strategic assessment } \\
\text { of the overall potential } \\
\text { impact and benefits of } \\
\text { blockchain for } \\
\text { organisations }\end{array}$ & $\begin{array}{l}\text { Axios (2018); Drescher (2017); lansiti and Lakhani (2017); } \\
\text { IBD (2018); Lacity (2018); Levine (2017); Michelman } \\
\text { (2017); Ølnes et al. (2017); Rabah (2017); Staples et al. } \\
\text { (2017); Swan (2015); White (2017); Ying et al. (2018). }\end{array}$ \\
\hline $\begin{array}{l}\text { Hurdles to } \\
\text { Adoption and } \\
\text { Blockchain } \\
\text { Limitations }\end{array}$ & $\begin{array}{l}\text { Assessment of the } \\
\text { many barriers that } \\
\text { could limit the take-up } \\
\text { of blockchain based } \\
\text { systems and wider } \\
\text { large scale adoption. }\end{array}$ & $\begin{array}{l}\text { Axios (2018); Bailis et al. (2017); Beck et al. (2016); Beck et } \\
\text { al. (2017); Böhme et al. (2017); Coyne \& McMickle (2017); } \\
\text { Drescher (2017); Forester (2018); Gomber et al. (2018); Guo } \\
\text { and Liang (2016); Hawlitschek et al. (2018); Holub \& Johnson } \\
\text { (2018); lansiti and Lakhani (2017); Kshetri (2018); Kshetri } \\
\text { (2017); Kypriotaki et al. (2015); Levine (2017); Ølnes et al. } \\
\text { (2017); Peters and Panayi (2016); Staples et al. (2017). }\end{array}$ \\
\hline
\end{tabular}

\subsection{Blockchain themes}

This section elaborates on the key themes listed in Table 1 outlining a number of the key factors from the existing research to develop a detailed narrative on IS related aspects of blockchain technology.

\section{Commercial Considerations and Realities}

Generally, the literature has presented blockchain as a technology able to solve a number of business problems due to the inherent characteristics of the technology and its potential to revolutionise the way we do business (Rabah 2017; Zalan 2018). This propensity within existing research to position blockchain as an enabler for technological change, perhaps masks the reality that few large scale commercial applications currently exist (Axios 2018). Some aspects of the media have reported that at least 75 banks across the globe are planning to implement blockchain solutions and that Facebook is secretly developing a large scale bespoke blockchain based cryptocurrency system (Independent 2018). These reports highlight the underlying interest and perceived benefits for organisations looking to invest in this technology. However, areas within the literature have endeavoured to look through a more sceptical lens in an attempt to offer a more holistic appraisal of the technology. The research by Dobrovnik et al. (2018) takes a pragmatic view of blockchain innovation within logistics, where it sets out the key attributes of blockchain and poses the question "how is the technology better than current practice?" The authors apply the framework developed by lansiti and Lakhani (2017) using the 
dimensions of novelty and coordination effort to better understand the true value potential for organisations. The study concludes that blockchain has the potential to deliver considerable savings in the context of operational efficiencies and reduced transaction costs, but significant challenges must be overcome before the technology can engender mainstream adoption. The pragmatic emphasis on the commercial benefits to the organisation is continued in Drescher (2017), where the study sets out the criticality of an "added value" perspective when comparing traditional centralised systems to blockchain based peer to peer architectures. The reality is that integrity within a blockchain network is expensive when compared to centralised systems. Therefore, organisations need to address the commercial realities when assessing the perceived benefits vs centralised based solutions (Drescher 2017).

Although numerous studies have extoled the virtues and transformational nature of blockchain technology, the large-scale, widespread deployment of blockchain solutions is not imminent and many prospective commercial applications are still at the prototype or feasibility stage. (Forester 2018; Holub \& Johnson 2018). Blockchain applications are likely to be developed by organisations within specific sectors such as finance, logistics and supply chain, where the potential benefits can be realised, rather than an industry wide adoption of the technology. The study by Kshetri (2018) emphasises this point where it discusses the feasibility project developed by Walmart and IBM to use blockchain technology to specifically monitor food based products in the US and China. The blockchain solution helped significantly reduce the time taken to track food from days to minutes delivering commercial and sustainability benefits to both organisations (Kshetri 2018). Although organisations seem to be actively reviewing blockchain at a strategic level, the daunting challenges in the areas of standards, regulations, shared governance models and viable ecosystems, highlights the immaturity of the technology (Lacity 2018). The study by Ying et al. (2018) documents one of the few commercial blockchain applications developed for the Hainan Airlines (HNA) group in China. HNA developed a blockchain based e-commerce system for its employees to buy products directly from $3^{\text {rd }}$ party suppliers. The system went online in February 2015 with 2000 suppliers participating and was viewed as a successful implementation (Ying et al. 2018). However, although this project has yielded lessons learned for the potential of blockchain, the study is limited as the system was available to internal customers only and no direct comparison to traditional centralised approaches was carried out.

Organisations should be cognisant of the potential business risks associated with blockchain solutions while still able to leverage the opportunities and benefits of its adoption (Staples et al. 2018). The commercial realities of blockchain were reviewed in Michelman (2017), where the study explored the topic from a pessimistic narrative to identify the true benefits - posing the question: What fundamental costs does blockchain reduce? The research highlighted cost benefits in two areas: 1) reduction in costs associated with transaction audit and verification, 2) the costs of exchanging value between parties due to not relying on a costly intermediary. The study associated these commercial benefits with the inherent characteristics of blockchain and its ability to securely record and timestamp all transactions within each block (Michelman 2017).

\section{Security, Privacy and Trust}

People are likely to interact and transact with a system if they trust it. Integrity in a system is required to fulfil the expectations of users and to reinforce their trust in the network. However a collaborative process execution is problematic if the participants involved have a lack of trust in each other (Dreschler 2017; Fosso Wamba 2018; Weber et al. 2016). Blockchain technology creates a trusted transparent environment making information publicly available thought the entire network, whilst assuring the integrity and immutability of data (Seebacher and Schüritz 2017; Ying et al. 2018). Within traditional networks, trust and integrity are handled via the central node or database that assumes the role of trusted $3^{\text {rd }}$ party. Developing and retaining integrity in a blockchain requires knowledge of 
the number of nodes and knowledge of the trustworthiness of the peers. The distributed peer to peer nature of the blockchain means that trust is integral to each block in the chain (Beck et al. 2016; Gomber et al. 2018).

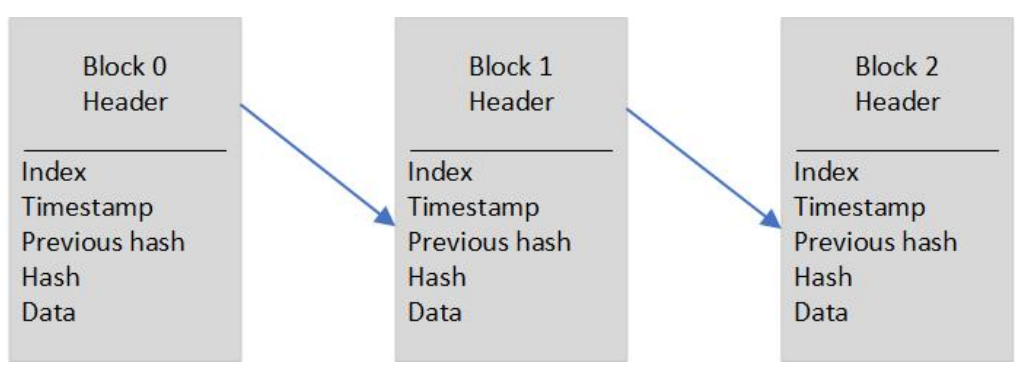

Figure 2: Simplified blockchain ledger (Source: Adapted from Aste et al. 2017)

The integrity of the blockchain is maintained via the structure of each block (Figure 2), where a full audit trail is detailed for all transactions and only valid transactions are added to the blockchain. (Drescher 2017). As the blockchain is engineered with immutability as one of its core characteristics, this fact is viewed as a guarantee of authenticity and trust, thereby increasing security and reducing the potential for fraudulent transactions (Fengi et al. 2018; Guo and Liang 2016). Blockchain assures the provenance of data as well as a security model that is fault tolerant and resilient (Lacity 2018). The trust concept is perhaps a step change for users, in that although the blockchain adopts a trust based architecture, institutional factors mean that confidence is required in the security of the technology prior to widespread adoption (Hawlitschek et al. 2018; Lacity 2018; Pazaitis et al. 2017).

The challenge within a working blockchain is to keep the network open to all valid parties, yet secure the history and integrity of data from being compromised by malicious $3^{\text {rd }}$ parties (Mendling et al. 2018). These elements together, protect the history of blockchain data from any manipulation by dishonest nodes or $3^{\text {rd }}$ parties. The study by Lacity (2018) highlighted that blockchain applications engender increased levels of security when compared to traditional architectures as they ignore faulty, malicious or suspicious transactions and nodes. Blockchain applications promise high levels of security resilience and availability. In the event of an attack on the blockchain itself, the network itself is resilient enough to be able to operate normally even if a high percentage of nodes are attacked (Lacity 2018).

\section{Business Model and Business Processes Implications}

Blockchain has been described as a foundation technology where the impact on organisations could be transformative, however, aspects of the literature argue that the change could take decades for blockchain to impact the business, economic and social infrastructure (Iansiti and Lakhani 2017). Organisations that implement blockchain based applications are likely to require significant changes to a number of business processes during the migration from traditional application architectures and even consider alternative business models (Tan et al. 2018; Weber et al. 2016). The study by Dobrovnik et al. (2018) explored the disintermediation potential for blockchain within the logistics industry highlighting the significant change in business process negating the need to employ 3rd-parties to verify the transfer of product ownership, as is the case with a traditional system structure (Dobrovnik et al. 2018). The smart contract capability of blockchain technology, widely discussed in a number of studies (Avital 2018; Bailis et al. 2017; Kshetri 2018; Mendling et al. 2018), requires a significant change to a number of business processes to accommodate the distributed infrastructure and changes to the trust relationship between parties. Kypriotaki et al. (2015) discussed how blockchain could enable fully 
decentralized forms of business structures to emerge, positing the impact on organisations from Decentralized Autonomous Corporations (DACs). The study described DACs as autonomous business entities running on the cloud, utilising blockchain technology, providing specific services and creating significant value to customers (Kypriotaki et al. 2015).

Blockchain technology and its application to Business Process Management (BPM) seems to be at a critical juncture as technological barriers are broken down and processes are decentralised whilst promising application scenarios and innovative business models are emerging (Mendling et al. 2018; Peters and Panayi 2016; Prybila et al. 2017; Zamani \& Giaglis 2018). Studies have articulated the reality that beyond the technology hype, transitioning to blockchain is about the changes and impact on the business and its stakeholders and not about technology. Organisations that have embarked on projects to join the latest trend are likely to see their efforts fail, whereas those that see the true value of blockchain and are able to reinvent their entire business processes, are likely to achieve the greatest benefits (Forester 2018; Michelman 2017; Ying et al. 2018).

\section{Cost \& Performance}

The assessment of accurate costs associated with a blockchain solution is problematic in that few studies have developed an extensive empirical analysis of blockchain applications beyond prototypes and feasibility studies. The research by lansiti and Lakhani (2017) discusses the transition to blockchain and aligns the technology adoption with that of TCP/IP in the early 1990s. The study highlights the emerging use of TCP/IP and the key pivot point of the technology gaining enough critical mass to engender confidence for wider adoption (Iansiti and Lakhani 2017). Substantive progress on industry wide blockchain deployment along the lines of the TCP/IP scenario, requires a transparent and pragmatic assessment of implementation costs and performance across a range of criteria. In the current state of blockchain technology evolution, this is perhaps problematic requiring significant risk and investment. Assuming a scenario where adoption of blockchain technology is a realistic option for organisations, senior managers must be cognisant of the true cost and ultimate business case for their blockchain applications.

The cost implications of moving to a blockchain based smart contract solution is referenced in a number of studies (Bailis et al. 2017; Beck et al. 2017; Gomber et al. 2018; Hawlitschek et al. 2018; Staples et al. 2017). This specific application of blockchain has been associated with significant cost savings, performance improvements, reduction in human error and eliminating the need for paperbased procedures within a supply chain management and financial transaction context (Dobrovnik et al. 2018; Holub \& Johnson 2018). However, as few real life applications of blockchain currently exist, any accurate costings are indicative figures and as such are subjective. Blockchain applications are likely to incur a low cost, one time transaction and storage fee, but the execution in a smart contract scenario is estimated to be more expensive that conventional infrastructure solutions (Staples et al. 2017). Organisations need to be pragmatic in their migrations to blockchain technology and approach this topic from a benefits and potential cost reduction perspective. The study by Michelman (2017) discussed these issues posing the question: "can blockchain reduce costs in a significant way? "The research explored potential savings specific to verification costs within the blockchain architecture. Specifically, this centred around the costs of audit and verifying the attributes of transaction as well as the costs of exchanging value between the parties. The study concluded that settlement and reconciliation processes across organisations would be simpler and more efficient and could lead to significant cost savings (Michelman 2017). The research by Rimba et al. (2017) explored the cost models and business processes in a study that compared the potential costs of Ethereum blockchain applications vs Amazons Simple Workflow Service (SWF). The results highlighted the significant cost variance between the two solutions concluding that in its current form the costs of blockchain were prohibitive for the selected business process (Rimba et al. 2017). 
There are likely to be limitations with specific blockchain solutions when compared to traditional approaches. In the smart contract scenario as discussed in numerous studies, the immutable nature of blockchain means that any amendments to the smart contract, however small, are likely to be computationally expensive requiring a new block in the chain and will have a cost and time implication for all parties. The costs of implementing a blockchain solution may be more than monetary. The research by Beck et al. (2017) articulates the case for a more critical perspective on blockchain in the context of risk and unintended consequences, concluding that the costs of the technology should be assessed along with social and geopolitical criteria (Beck et al. 2017). These factors are also emphasised in Dresher (2017) where the high costs and limited scalability of blockchain are expressed in terms of: computational cycles, time, energy and money. The study by Mendling et al. (2018) highlights costs in the context of increased latency, usability limitations, security issues, size and bandwidth limitations, all of which need to quantified and assessed from a risk perspective by the organisation.

\section{Cryptocurrencies and Online Transactions}

The execution of financial transactions via protocols such as Bitcoin, Litecoin, Namecoin and Ethereum via blockchain technology, although not yet a mainstream ubiquitous process, is now an established model and method for a growing number of organisations. Bitcoin is the most established and widely used of the cryptocurrencies, relying on two key technologies: public, private key cryptography, to store and spend money and cryptographic validation of transactions (Tang et al. 2019; Tasca et al. 2018). The underlying processes inherent within each of these technologies ensures transaction history immutability and high levels of security for all executed transactions (Böhme et al. 2017; Li \& Wang 2017). The Bitcoin transaction process is detailed in figure 3 where an example of a simple transaction is described. Cryptocurrencies rely on the concept of mining which effectively acts as a distributed consensus system to confirm pending transactions based on Proof of Work (PoW) (Aste et al. 2017). The mining process enforces verification, chronological order and neutrality throughout the blockchain allowing all nodes in the network to agree on the state of the system (Bitcoin 2019). Miners are rewarded in Bitcoins as they successfully solve a cryptographic puzzle that leads to a recording of transactions within the blockchain (Eyal \& Sirer 2018).

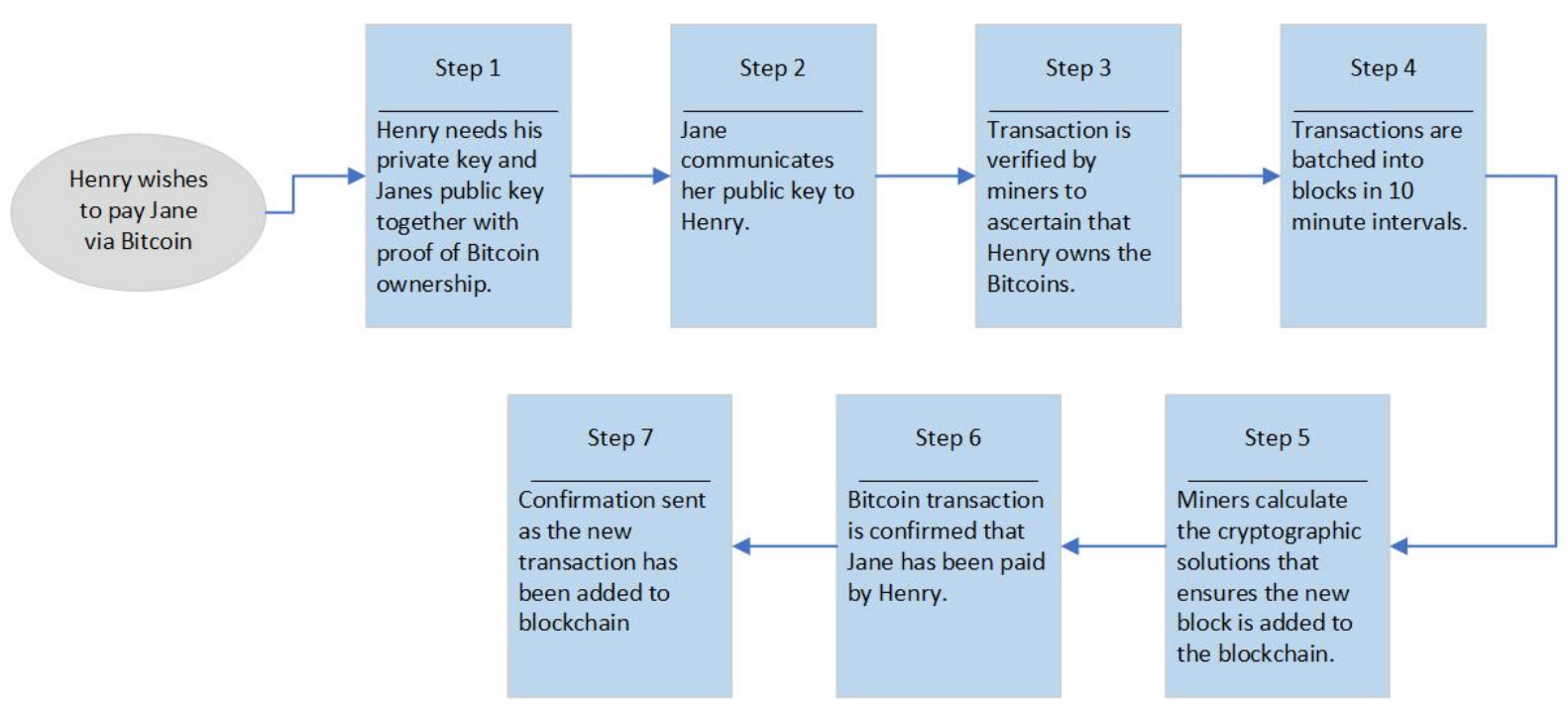

Figure 3: Bitcoin transaction process 
Validated bitcoin transactions are added to the blockchain in batches of approximately ten minutes. Individual miners are continuously developing and presenting solutions to the cryptographic puzzles, effectively voting on the verification of each transaction prior to any new block being added to the network.

Cryptocurrencies and the use of blockchain technology has delivered significant benefits to specific transaction use cases, but major obstacles exist to the widespread use of this form of transaction. Studies have highlighted the high resource costs of recording all Bitcoin transactions across the network, the computational burden, high data storage costs and cultural issues inherent in the wider use of the technology (Fosso Wamba et al. 2018; lansiti and Lakhani 2017). The anonymity aspect of Bitcoin transactions could also be problematic as more formal governance and regulatory compliance and approval is sought (Holub \& Johnson 2018). The lack of no single central owner for the Bitcoin network makes oversight difficult and is likely to be another barrier for formal governance and wider regulatory approval in the future (Staples et al. 2017; Zamani and Giaglis 2018).

\section{Potential blockchain Business Applications}

The literature has identified a number of potential blockchain based applications that are deemed to offer advantages over traditional based architectures. These are listed in table 2.

Table 2: Blockchain applications from the literature

\begin{tabular}{|l|l|}
\hline Blockchain Application & Study Reference \\
\hline Peer review system & Avital, (2018) \\
\hline Smart contracts & $\begin{array}{l}\text { Bailis et al. (2017); Beck et al. (2017); Gomber et } \\
\text { al. (2018); lansiti and Lakhani (2017); Ølnes et al. } \\
\text { (2017); Peters and Panayi (2016); Staples et al. } \\
\text { (2017); Swan (2015). }\end{array}$ \\
\hline Online dispute resolution & Barnett \& Treleaven (2018). \\
\hline Trust based payments & Beck et al. (2016). \\
\hline Expert system & Carrenõ et al. (2018). \\
\hline Accounting and assurance & $\begin{array}{l}\text { Coyne \& McMickle (2017); Dai \& Vasarhelyi } \\
\text { (2017). }\end{array}$ \\
\hline Distributed collocation storage architecture & (Fengi et al. 2018). \\
\hline Payment clearing and credit information & Guo and Liang (2016). \\
\hline Supply chain management and logistics & $\begin{array}{l}\text { Dobrovnik et al. (2018); lansiti and Lakhani } \\
\text { (2017); Kshetri (2018); Levine (2017); Queiroz } \\
\text { and Wamba (2019); Staples et al. (2017). }\end{array}$ \\
\hline $\begin{array}{l}\text { knowledge sharing in manufacturing } \\
\text { ecosystems }\end{array}$ & Li et al. (2018). \\
\hline
\end{tabular}

Studies have generally reviewed the potential of blockchain and applied it to specific use cases where the merits and inherent characteristics of the technology are applied to problem scenarios. The most frequently discussed genres of blockchain applications are: smart contracts, supply chain management and logistics. The technological characteristics of blockchain lend themselves to the processing of smart contracts where settlement and financial payments can be automatically triggered by specific events. The study by lansiti and Lakhani (2017) discusses a smart contract scenario where blockchain technology is used to automate a payment to a supplier as soon as shipment is received. The blockchain would use GPS functionality that could track the goods, monitor delivery and trigger the payment from the vendor (Iansiti and Lakhani 2017). 
The technological characteristics of blockchain lend themselves to a number of use cases within the logistics and supply chain management area offering potential efficiencies and benefits to all parties. The traditional supply chain process relies on $3^{\text {rd }}$ party intermediaries that act as the guarantors of assets and the mechanism of assurance for ownership of goods. By implementing blockchain based solutions, via the distributed ledger aspect of the technology, all parties can automatically ascertain ownership of goods, approve shipping and trigger payments on receipt of goods (Dobrovnik et al. 2018). The study by Queiroz and Wamba (2019) analysed the blockchain adoption behaviour within supply chain management in the context of organisations within India and the USA. The research highlighted the criticality of facilitating conditions, social influence, and performance expectancy and how these factors can influence blockchain adoption. The study concluded that blockchain technology usage specific to supply chain management, is still at the infancy stage within these two countries (Queiroz and Wamba 2019).

Although the literature has articulated a number of applications that are identified as being suitable for blockchain, the reality is that few organisations have developed their systems beyond feasibility (Forester 2018; Holub \& Johnson 2018). Converting blockchain ideas from feasibility to widespread commercial reality is problematic with the realisation that organisations will need to allocate significant investment for blockchain projects (Axios 2018; Lacity 2018). Studies have highlighted the potential business value in areas such as: finance, marketing and legal (Tapscott and Tapscott 2017), whilst articulating a more subjective narrative highlighting current limitations and barriers to delivery of tangible benefits to the organisation. Senior management need to be aware of the potential impact of blockchain techniques, the changes to business processes and the potential opportunities of the technology. However, organisations must be wary of engaging in fruitless early stage application development until the true real business benefits are known (White 2017).

\section{Assessment of Benefits and Market Disruption Potential}

There are a number of benefits that have been cited as a direct consequence of implementing a blockchain solution. The studies by Drescher (2017) and Rabah (2017) itemise a number of these benefits, which are illustrated by Figure 4 and described below.

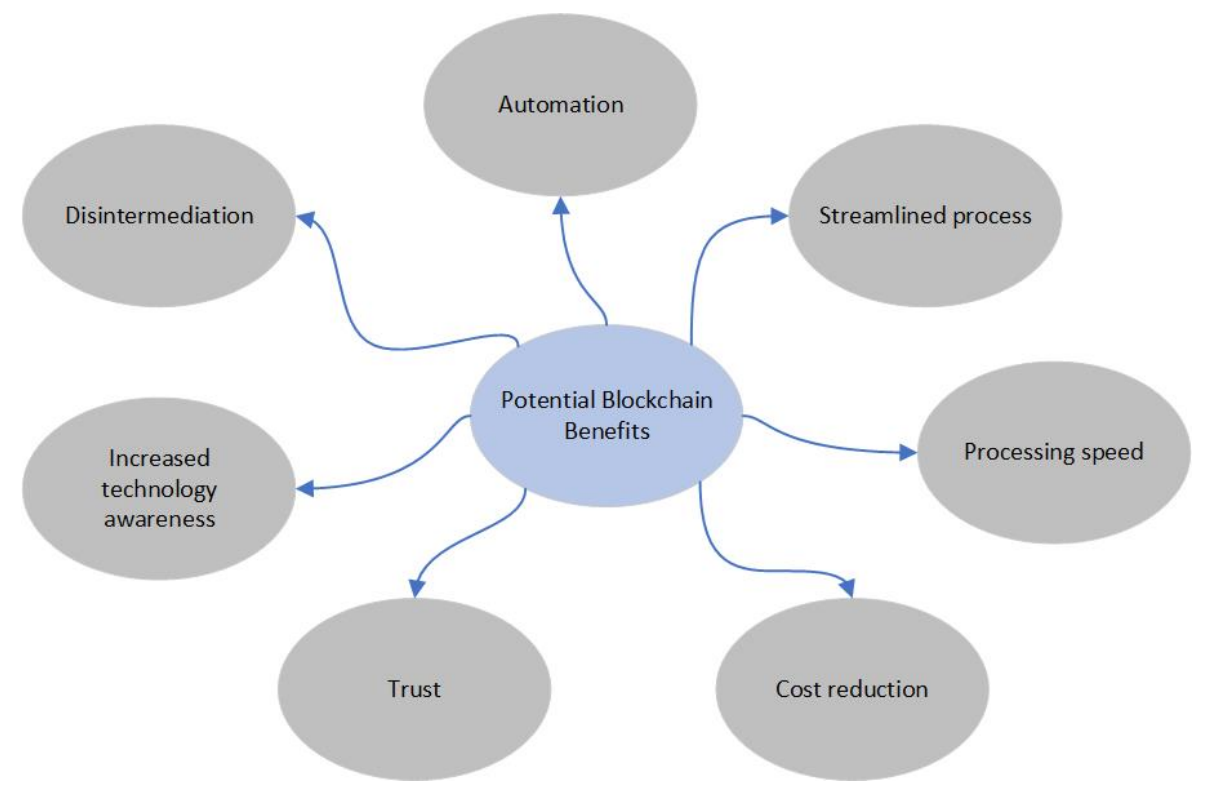

Figure 4: Potential blockchain benefits 
- Disintermediation - This refers to the reduction in need for intermediaries or $3^{\text {rd }}$ parties within the blockchain process. Traditional centralised processes require humans or additional technology to assure trust, with blockchain this is built in by default.

- Non-repudiation - This benefit relates to the integrity of the blockchain where parties cannot deny or dispute their additions to the blockchain due to the integrity of the transaction history.

- Automation - The working mechanism of blockchains can replace manual labour tasks if the specific use case utilises automated interactions between parties.

- Streamlined process - Under blockchain, business processes will become more standardised, transparent and streamlined as they are redesigned for the transition from traditional technologies.

- Processing speed - The increased use of automation within blockchain processes when compared to centralised architectures is likely to deliver significant execution speed benefits for specific use cases.

- Cost reduction - The net effect of disintermediation and automation is a reduction in costs for those applications that can take advantage of blockchain technology.

- Trust - Blockchain effectively replaces trust in humans with verification and trust in technology and associated protocols. This is likely to be a significant business change from current working practices. Trust in the integrity of security and payment processing could evolve into a commodity as blockchain becomes ubiquitous and costs begin to fall.

- Increased technology awareness - This is perhaps a side benefit of implementing blockchain, but via the increased awareness and use of this technology, new applications and new understanding is developed.

The list of benefits listed above is supported in Ølnes et al. (2017) under the categories of: strategic, organisational, economic, international and technological where the study discusses the potential of blockchain technology through the lens of government organisations. Further studies have extoled the advantages for organisations if they adopt blockchain technology, citing the benefits of the distributed ledger architecture (Lacity 2018; Swan 2015; White 2017; Ying et al. 2018).

The literature is inconsistent on the assessment of the disruptive potential of blockchain, where researchers either articulate the significant drivers for the technology or seem to urge caution and pragmatism as entire ecosystems may need to adapt (Michelman 2017; Staples et al. 2018). The study by lansiti and Lakhani (2017) argues that blockchain is not a disruptive technology but is in reality a foundational technology. The authors predict that blockchain has the potential to engender new economic and social systems, emphasising that this change although enormous, will take decades to impact our economic and social infrastructure (Iansiti and Lakhani 2017). The process of adoption is likely to be gradual and steady as more blockchain applications are developed and organisations can visualise the benefits (Lacity 2018). The planned 2019 launch of tZero - the first SEC-cleared digital security token, is cited as an example of blockchain driving disruptive change to global equity and financial markets (IBD 2018). The A.P. Moller-Maersk A/S and IBM project discussed in Levine (2018) highlights the positive and disruptive potential within logistics for blockchain applications that govern the transportation and tracking of shipping containers (Levine 2017). The Walmart and IBM case study discussed in Kshetri (2018) supports these findings where Walmart reported that blockchain helped to reduce the time taken to track food from days to minutes (Kshetri 2018). Further studies have articulated the potential for blockchain but seem to develop a more cautionary and evolutionary narrative. The research by Rabah (2017) highlights the radical innovation potential of blockchain, but 
argues that adoption is likely to be industry genre specific where certain sectors such as finance are deemed to be sufficiently mature to engender the development of new applications (Rabah 2017).

\section{Blockchain Limitations}

Blockchain technology has the potential to offer a number of distinct benefits when compared to traditional centralised architectures. However, the technology exhibits a number of limitations that need to be factored into any business case for adoption (Beck et al. 2016; Gomber et al. 2018). Aspects of the literature (Axios 2018; Böhme et al. 2017; Coyne \& McMickle 2017; Drescher 2017; Forester 2018) have identified the following limitations with blockchain technology:

- Lack of privacy - Each node in the network maintains the complete history of the networks transaction data. This maybe an attribute for specific applications and an advantage in a security context, but a limitation for use cases where privacy is a necessity.

- High costs - The underlying processing of the blockchain where all the transaction history is replicated across all nodes, is computationally expensive. This attribute has security advantages but can be a limitation for larger networks.

- Security model - Blockchains use public key encryption for transaction authentication and execution. This process although very secure, requires the use of a public and a private key. If in the event that a party loses or unwittingly publishes their private key, the system has no safety mechanism to provide additional security.

- Flexibility limitations - The immutable append only characteristics of blockchain ensures the integrity of transactions are assured, but can act as a barrier to use cases that require changes to transactions.

- Latency - The principle of all nodes within the blockchain network storing the complete transaction record of all information blocks ensures the networks security credentials, however, the addition of new blocks and subsequent transaction records is at present computationally expensive.

- Governance - The distributed nature of the blockchain architecture offers distinct advantages for specific use cases but can be a significant limitation for overall control and governance by oversight based organisations.

The above list of limitations outlines some of the specific technical challenges and unintended consequences that may limit the development and commercial adoption of blockchain technology. Non-technical limitations include: lack of acceptance from legal and regulatory authorities; lack of user acceptance. As blockchain technology is relatively recent, organisations have yet to fully tackle these key obstacles and could pose significant threats to the wider acceptance of the technology. Questions remain regarding legality of transactions, privacy and GDPR adherence, resistance amongst users due to poor levels of knowledge and trust in the technology (Drescher 2017; Kshetri 2017; Kypriotaki et al. 2015; Levine 2017). Limitations also exist in the context of blockchain operating within key application genres. One example is discussed in Staples et al. (2017), where the study highlights the inherent limitations of blockchain to cater for big data storage or other high velocity data storage applications due to poor performance (Staples et al. 2017).

Studies have highlighted the limitations of blockchain specific to application genres. The study by Guo and Liang (2016) discussed the potential obstacles to blockchain in the context of the banking industry articulating the case for some form of centralisation to establish the necessary governance and control (Guo and Liang 2016). There are significant obstacles for blockchain adoption within the financial sector. The regulatory requirements to record all transaction by every member of the network is likely to very costly in terms of resources. The potential computational burden and data 
storage costs on the network could be a real limitation as transaction numbers grow (Holub \& Johnson 2018). Aspects of the literature have extoled the key advantages of blockchain specific to the smart contracts use case. Here logistics and supply chain management can benefit from the automation of settlement and authentication of blockchain (Iansiti and Lakhani 2017; Kshetri 2018; Levine 2017; Staples et al. 2017). However, the immutability characteristics of the technology also pose limitations for this genre of application, namely: poor scalability, requirement for explicit intervention for execution and inability to adjust contract terms (Hawlitschek et al. 2018).

As is the case for any new and potentially transformative technology, substantial risks exist for any organisation looking to develop business critical applications using blockchain. Organisations seem to over-emphasise the technology innovations behind blockchain rather than focus on the true underlying business benefits ( $\varnothing$ Ines et al. 2017; Peters and Panayi 2016). The migration to blockchain will require significant investment and executive commitment over a not insignificant length of time. This is likely to be a limiting factor for many organisations who will opt for a wait and see approach rather than risk the potential of significant impact on the organisation due to a failed blockchain implementation (Iansiti and Lakhani 2017). In addition to the aforementioned limitations, blockchain projects should also consider success and failure factors specific to IS/IT project as outlined by existing studies (for example, Dwivedi et al. 2012; 2015; 2013; Hughes et al. 2015; 2016; 2017; 2019).

\section{A view from practice}

The ongoing investment in blockchain product development within industry and government organisations, highlights an acceptance that the technology offers transformative change across many sectors, lending credence to its disruptive innovation characterisation (White 2017). Organisations are reviewing their processes and business models seeking to identify the key use cases where blockchain can add value and deliver benefits (Ying et al. 2018; Zamani \& Giaglis 2018). Emerging markets are proving to be an area where the potential application of blockchain is increasingly viewed as a viable solution to address issues such as trust and transparency between parties. Blockchain technology is engendering significant attention within India across a wide range of industrial sectors for a range of use cases including: trade finance, supply chain financing, e-KYC document management, cross-border payments and patient record management (Deloitte.com 2019). The recently announced blockchainlinked funding for SMEs by a consortium of leading Indian banks, highlights the appetite for significant investment in blockchain where benefits are perceived to be deliverable in the short to medium term (Economic Times 2019).

One of the many challenges facing industry is one of how to deliver the promise of blockchain whilst addressing the key limitations of the technology: transaction latency, privacy and lack of flexibility. Solution providers have needed to seek innovative solutions to these sorts of issues to meet the requirements of vendors looking for blockchain applications. In scenarios where high transaction rates are required for financial applications with multiple stakeholders, limited technical solutions exist to accommodate these requirements. With an increasing number of participants on the chain such as traders, bankers, freight forwarders, insurance companies, the number of blocks would only increase to a level where mining becomes more cumbersome and time consuming. Indian blockchain technology company - SimplyFI have sought to address some of these issues with the implementation of an Ethereum based platform, where the solution entails the adaptation of the underlying architecture to mitigate some of the inherent limitations of the technology. This necessitates the introduction of a queuing layer that effectively delays the request to the blockchain system, thereby increasing the transaction speed across the network. Implementing a queuing layer helps achieve a 
higher scale of transactions and improves efficiency to reduce the risk of overload (SimplyFl.tech 2019).

Another challenge impacting the financial industry and the migration toward blockchain, is the lack of a common architecture across industry and integration/communication with transactional based systems. The net effect of no adopted consensus architecture, is the lack of interoperability amongst multiple blockchains and the reliance on workarounds to reconcile data back to legacy systems. Solutions to these problems are at an early stage with organisations assessing the feasibility of approaches using Hyperledger (an open source solution hosted by the Linux Foundation) and Tendermint (general purpose blockchain consensus engine able to host arbitrary application states). However, such protocols are still in their infancy and fall short of building robust integration between blockchains. Interoperability requires extensive further research to analyse solutions to interblockchain communication and integration with transactional systems.

Significant benefits could be achieved industry wide by the convergence of blockchain, Internet of Things (IOT) and Artificial Intelligence (AI). Many loT use cases are relevant to manufacturing and logistics value chains where loT enabled devices allow real time global asset tracking. Blockchain applications that are loT enabled, can offer an end to end solution where smart contracts can govern the trusted secure transaction and payment, whilst loT technology can track assets in real time.

\section{Addressing Grand Challenges: Blockchain potential application examples and recommendations for the public sector service delivery in a developing country}

Whilst a number of studies have detailed specific scenarios or use cases where blockchain has the potential for delivering significant change and benefits to organisations and citizens, many lack specific context offering generalisation and a high level narrative. The study by Queiroz and Wamba (2019) explored the blockchain adoption behaviours specific to SCM within India and the USA, highlighting the variances in attitudes between the countries. The study highlighted the influence that trust has on emerging economies willingness to adopt blockchain solutions, emphasising the issues with current processes and potential for distrust amongst stakeholders. Furthermore, the results of the study reinforce the impact of social influence and its positive effect on blockchain adoption within India and potentially other emerging economies (Queiroz and Wamba 2019). These regional and cultural drivers are supported within other aspects of the literature where studies have highlighted the key aspect of trust and behavioural intention within a number of contexts (Francisco and Swanson 2018; Kshetri 2018; Thiruchelvam et al. 2018). The potential for blockchain solutions to make an impact within an emerging nation such as India, is significant. One specific instance is the potential impact that blockchain technology could have on the life of Indian migrants and their families. The second is the positive impact that blockchain technology could have on the income of Indian farmers.

\subsection{Potential application example 1: Indian Migrant crisis}

Millions of Indian migrants travel from rural areas such as: Bihar, Uttar Pradesh, West Bengal, Chhattisgarh, Odisha and Rajsthan to cities each year in search of employment. While estimates vary, historical census figures (circa 2001) state that over 90 million people migrate to areas such as: Gujrat, Maharashtra, Delhi, Karnataka, Kerala and Tamil Nadu in search of work and a better life. The Migration Policy Institute (2014) highlights that The 2001 census counted about 191 million people or 19 percent of the total Indian population at the time, as internal migrants who had moved long distances to other districts or other Indian states to live and work. Many migrants, especially those who relocate to a state different in terms of culture and local language, face significant hardship, 
harassment and political exclusion. Political responses to India's significant internal migration issues are limited and existing legislation - supposed to provide for workers' rights, is seldom enforced. Nongovernmental organisations often fill the gaps in welfare services, education, and labour rights that are left by the government (Migration Policy Institute 2014).

The Targeted Public Distribution System (TPDS) was established in 1997 to supersede the Public Distribution System (PDS) as the process and mechanism by which subsidised food products are distributed to people defined as living Below Poverty Line (BPL) within India's rural and urban areas (India.gov 2019). A Planning Commission 2005 study on the TPDS highlighted that close to 58 percent of the subsidised food grains issued from the central pool do not reach the BPL families due to: high cost of handling food grains by public agencies, identification errors, non-transparent operation and unethical practices (Planning Commission 2005). The scope and mandate of the TPDS expanded significantly in 2013 via the National Food Security Act (NFSA) passed by the Government of India (Gol). The NFSA combined the three core programs: TPDS, Mid-Day Meal Scheme (MDMS) and Integrated Child Development Services (ICDS). The NFSA entitles 50 percent of the urban population and 75 percent of the rural population to receive food benefits under the TPDS, which is the largest of these programs (WFP 2014). The current reality in the implementation of the NFSA is that migrants having moved from one state to another, do not get access to the PDS system of their new state even if they hold BPL ration card of their home state. This is primarily due to a number of factors:

- the resource constraints of the destination state and the caps placed by government on quotas mean that there is a disincentive to provide for out of state migrant families,

- no centralised database exists for BPL families as the list is prepared by each state independently, with the effect that migrating family units may not be categorised as BPL status in a different state,

- verification of BPL status between states is further complicated by language barriers, format inconsistences and no independent validation.

The net affect of the above is that millions of BPL migrant families are not provided for by the TPDS or any of the NFSA schemes and end up living in extremely poor conditions reliant on Non-Government Organisations (NGOs) to survive.

\section{How blockchain technology can deliver benefits to India's migrant population}

The inherent characteristics of blockchain in particular the immutability, security, transparency and trust elements of the technology lend themselves to offering potential solutions to migrant support within India. In a blockchain application scenario - the data relating to each migrant worker such as their unique ID, BPL status, existing ration card (PDS card) reference as well as their monthly PDS transaction record, could be added to the blockchain. This could potentially act as a trusted, undisputed PDS transaction for all parties. The Gol could aggregate the migrant grain allocation for the destination state based on the home state allocation to ensure minimal additional financial burden on the destination state. The migrant families could obtain their food grains at the nearest ration outlet without completing forms or visiting government offices. This process could be facilitated via the use of a blockchain supported smart card which would be connected via a national cloud based infrastructure. This blockchain driven process could ensure that states would not use additional resources and that the Gol would not incur additional subsidy burden. Success would be dependent on political support via Gol multiparty agreement allowing PDS access to cross-state BPL migrant records. 
Areas where blockchain could potentially make a significant positive change to Indian migrant families are: health and education. Blockchain technology could be used to incorporate migrant children's school records allowing them to seamlessly transfer and get admission in government run schools regardless of which state provides the education. This system could also ensure school age children would automatically enrol in the MDMS of the new school thereby providing adequate support for their health and education. Migrant family's medical history can also be added to the blockchain record as well as social welfare schemes including: pensions, pregnant mother health incentives and other welfare benefits.

The verification and validation of identification documents relating to out of state migrants is fraught with problems relating to: lack of standardisation, language issues and formal acceptance criteria. The key factors for a blockchain solution that could greatly benefit these problems are:

- Data protection and privacy: Most blue collar migrants are categorised as semi-literate and possibly unaware of issues relating to information security and data theft. Unscrupulous agents could potentially misuse this information for their own means. Migrants data protection and privacy could be protected via an encrypted blockchain.

- Logistics and carriage: Migrants and their families are unlikely to carry multiple documents such as birth certificates, school enrolment details, ration cards and medical records. Furthermore, these records are likely to be state and language specific and may not be accepted by the destination state.

- Transparency, reliability and verifiability: Agencies would be able to trust, accept and verify the records of migrant families using blockchain applications. This process would greatly enhance current processes and protect against misuse and fraud within the PDS system.

\subsection{Potential application example 2: Indian farming income}

Supported by favourable monsoon rainfall, India produced 284.83 million tonnes of food grains in the 2017-18 crop year (Times of India 2018). This compares to 51 million tonnes in 1950-51. However, Indian farmer income has risen just 3.5\% between 1993-94 and 2015-16, highlighting the fact that prices have remained stagnant for over a decade. The Gol has initiated an ambitious goal to double farmer income by 2022 to address the disparity between farmers and those working in non-agriculture professions. One of the six areas of focus detailed in the Niti Aayog policy paper (Niti.gov 2019), highlights the improvement in real prices received by farmers and the e-National Agriculture Market (e-NAM) initiative of the Gol. The scope of e-NAM includes an initiative to break the intermediary agents' monopoly over agricultural markets. The net effect of this policy change is an opening up of the whole country as a market for farmer's produce. This change in theory is possible but inherent problems exist relating to grading of commodities and trust of parties. The grading scale must be automated, uniform and independent of geographical location of the produce. The standards must be such that a buyer sitting in Hyderabad should confidently procure pineapples from Nagaland over eNAM, or a cotton trader in Mumbai must be able to place orders for cotton available in Guntur. Trust between parties is a factor here. How do we build trust into the e-NAM process to ensure all stakeholders have confidence that the transaction will progress in adherence to the contract?

Blockchain can provide a powerful trust backbone to help the farmers in two ways: (1) building the quality and confidence in the Farm Produce, (2) logging the agreed price paid to farmers within the blockchain record as a Fair Farm Price (FFP) rating. This process can act as a strong bulwark against farmer exploitation by building the FFP rating in the blockchain record that is visible across the supply chain. This would create a transparent mechanism for consumers and buyers to verify whether the produce they are buying is procured after paying a fair price to the farmer. These products when they reach the supermarket shelfs or online store's delivery warehouses would have a verifiable QR code 
which would be a publicly verifiable record of price paid to the farmer. Social marketing initiatives could reinforce changes in behaviours to be "Farmer Friendly' and ethically responsible along the lines of the Fair Trade movement. Consumers would have a choice to buy a slightly higher priced but a higher FFP rated product. A non-profit social alliance could be developed to provide FFP ratings to various products based on how fair the remuneration has been to the farmers. This would encourage the grocery stores (online as well as brick and mortar), restaurants, hotels and government procuring agencies to source their supplies from higher FFP rated suppliers.

\section{Discussion}

Blockchain technology is a complex technical construct that at its core utilises state of the art security protocols to maintain integrity within a distributed peer-to-peer network. Maintaining the integrity and immutability of transactions is central to the underlying process of blockchain and one of the key benefits of the technology. The disintermediation potential of blockchain is the second key benefit in that this specific attribute has the potential to act as a major driver for significant change throughout industry (Drescher 2017). The literature has analysed many of the key the attributes of blockchain developing a generally positive narrative on: possible use cases, specific applications as well as the market disruption potential of the technology (Kshetri 2018; ØInes et al. 2017). Further studies take a more pragmatic and cautious view, developing a structured critique of the technology where many of the limitations of blockchain are analysed in the context of specific use cases such as: supply chain and smart contracts (Axios 2018; Lacity 2018; Levine 2018).

Whilst many studies highlight the key benefits and potential limitations of blockchain, it is critical not to lose sight of the fundamental issues that blockchain is attempting to solve to ensure blockchain is not presented as a solution looking for a problem. Traditional network architectures rely on centrally controlled databases connected to a number of nodes, managed by layers of software and human administrators. This centralised structure can pose a number of issues but generally fall into the categories of technical failures and malicious peers. Technical failures include: infrastructure and software failures inherent within any traditional network. Malicious peers relates to the goals of individuals and entities that seek to exploit and control the network for their own purposes. Both of these categories of issues impact integrity and trust (Drescher 2017; Staples et al. 2017).

What does this mean in reality when we apply these underlying issues to specific use cases that currently incorporate traditional centralised infrastructures? If we take a simple supply chain scenario where goods are procured and transported from supplier to customer within a tracked logistics process. Problems can occur in evaluating ownership of goods, numerous intermediaries could be required along the supply chain for international goods transfer and interim settlement, contract terms and conditions may vary between parties within the supply chain, payment for goods and services can be delayed and in the international context, sometimes difficult to enforce. Blockchain technology attempts to deal with a number of these issues via its inherent immutability, establishment of integrity and trust throughout the network whilst delivering transaction transparency and efficiency (Dobrovnik et al. 2018; Hawlitschek et al. 2018).

The literature has explored the potential for blockchain to solve many of these issues associated with centralised architectures where some of the key benefits are reviewed within a number of use case scenarios. The ability of blockchain technology to establish a distributed ledger utilising smart contracts between parties for the transfer of goods or financial assets, could offer a significant change to established processes. This move from an environment where mechanisms and processes are builtin to establish trust, to an infrastructure where trustworthiness, integrity and non-repudiation are integrated within the infrastructure, is a powerful driver for adoption. Applications built around smart 
contracts are viewed as being the blockchain based innovation that has the greatest potential for transformative change. (Iansiti and Lakhani 2017). Smart contracts could automate payments when key conditions are met and where goods or services are delivered bypassing the need for intermediaries. This single innovation could have significant impact on the logistics industry, finance, contract law and even management accountancy in the context of reconciliation exchange of value, settlement and impact on existing business processes (Mendling et al. 2018; Michelman 2017). The concept of an immutable contract between parties where all transaction data is secure, where disintermediation and non-repudiation are a key principle with trust and integrity being a core integral component of the architecture, seems to be a powerful case for adoption by organisations and governments.

However, blockchain is currently at an important crossroads where the hype surrounding various cryptocurrencies has somewhat subsided and organisations are reviewing the reality of potential benefits to their business (Mendling et al. 2018). Organisations that have been early to move forward with their blockchain initiatives, are painfully aware that the technology is still at a very early stage of development and that significant commercial momentum for the technology is yet to materialise. This realisation is likely to result in a number of feasibility projects to invariably fail (Forester 2018). Studies have discussed some of the pragmatic observations of using blockchain in the context of unrealistic expectations especially as the technology matures. In the short term humans will still be required in the process, shipping containers will still need inspecting and immutability may end up being a limitation as well as a benefit in some use cases (Levine 2017).

The positive change that blockchain technology could facilitate, has been discussed in the context of two potential cases within the Indian public sector. These cases illustrate the change that the technology could potentially engender and the resulting impact on the lives of Indian citizens. This illustrates that perhaps a more accelerated diffusion toward blockchain is likely to be driven by emerging markets where the widespread adoption of the technology could yield greater benefits to users.

The pragmatic assessment of benefits is fundamental to any transition toward blockchain solutions. A premature rush toward blockchain for numerous applications when conventional architectures can offer a better and cheaper solution is a poor way to deliver business value. Developing substitute blockchain applications requires careful planning to ensure users can easily transition to the new technology and adopt new systems with the minimum of resistance (Kshetri 2017; Kypriotaki et al. 2015). Studies have posited that large scale transformative, commercial blockchain applications are still far away (Axios 2018; Forester 2018; Lynn et al. 2018). However, the potential benefits and range of applications that could use blockchain are extensive and this is likely to engender momentum for wider acceptance. Organisations would be wise to not ignore blockchain but to clearly understand the impact and potential change to current business models and working practices from widespread adoption.

\subsection{Blockchain and alignment with UN SDGs}

In 2015 the UN developed its vision of the future with the creation of the Sustainability Development Goals. The SDGs are positioned as a blueprint and shared agenda for future peace and prosperity for the planet and its population. The 17 SDGs emphasise the ending of poverty and other deprivations in alignment with strategies to improve health and education, reduce inequality, develop economic growth whilst tackling climate change and preserving our forests and oceans (UN 2018). The set of SDGs are listed in Table 3. The study by Ismagilova et al. (2019), incorporated the UN SDG's in the context of alignment with the researchers view on the future impact of Smart Cities and its citizens. 
This study follows the Ismagilova et al. (2019) view on the importance of positioning the relevant research outcomes and propositions in the context of the SDGs.

The SDGs that are deemed to align with the potential for blockchain technology are presented in table 3. Many of the factors are likely to have greater impact in scenarios where blockchain solutions are able to address a number of the infrastructure and integrity issues inherent with traditional architectures and processes. Additionally, solutions developed to attain specific UN goals offer greater benefits where blockchain technology can be integrated with big data, digital transformation and sustainability in the context of creating business and social value (Loebbecke and Picot 2015; Pappas et al. 2017; Pappas et al. 2018). Specifically, blockchain technology could address UN sustainability goals and topics relating to:

- Problems within but not exclusive to developing countries.

- Large geographical areas where the infrastructure is poor.

- In scenarios where governance and enforcement is inadequate.

- Where supply chains are long and the potential for corruption is high.

- In circumstances where people have lost trust in authorities with inadequate levels of transparency and integrity.

- Problems relating to the health and safety of citizens.

Table 3: UN sustainable development goals vs blockchain technology driven change.

\begin{tabular}{|l|l|}
\hline UN Sustainability Goals & Blockchain technology aims in delivering UN goals. \\
\hline No poverty & $\begin{array}{l}\text { Blockchain could make a significant change to aspects of } \\
\text { sustainability that impact health, the distribution of medication } \\
\text { and humanitarian supplies. In the case of developing countries } \\
\text { problems exist in the integrity of medicines and basic food } \\
\text { products where the challenge of enforcement and logistical } \\
\text { management across linguistic barriers and geographical } \\
\text { diversity is a huge challenge. The characteristics of blockchain } \\
\text { can offer significant benefits where parties can ship and monitor } \\
\text { the lifecycle of health-related goods relying on blockchains } \\
\text { immutability and transactional integrity to assure improvements } \\
\text { to health and wellbeing. }\end{array}$ \\
\hline Quality education & $\begin{array}{l}\text { The attributes of blockchain could deliver benefits in developing } \\
\text { countries where the technology could be used to assure quality } \\
\text { and commitment to education in all its forms. Financial and } \\
\text { logistical commitments to education and gender equality from } \\
\text { central and regional authorities would be embedded within } \\
\text { smart contracts between all parties. }\end{array}$ \\
\hline Render equality & $\begin{array}{l}\text { Contracts relating to the development of infrastructure required } \\
\text { to assure clean water, sanitation and energy could be managed } \\
\text { via blockchain technology ensuring fraud is minimised and } \\
\text { higher levels of trust are developed between the parties. }\end{array}$ \\
\hline Clean water and sanitation
\end{tabular}




\begin{tabular}{|c|c|}
\hline & $\begin{array}{l}\text { transparent and trusted approach could hasten ethical moves } \\
\text { toward industry innovation and fairness to exploited workers. } \\
\text { These factors can lead to greater levels of sustainability within } \\
\text { cities and communities where blockchain based contracts can } \\
\text { integrate sustainability requirements as an integral contractual } \\
\text { component. }\end{array}$ \\
\hline $\begin{array}{l}\text { Responsible consumption and } \\
\text { production }\end{array}$ & \multirow{4}{*}{$\begin{array}{l}\text { Gaining consensus on key global sustainable issues is one part of } \\
\text { the equation, however, the implementation and consistent } \\
\text { application of the agreements relating to the United Nations } \\
\text { Framework Convention on Climate Change (UNFCCC), } \\
\text { subsequent Kyoto Protocol (2013-2020) and Paris Agreement } \\
\text { (2015), is more problematic as individual countries interpret the } \\
\text { agreements. Blockchain could offer a framework and } \\
\text { mechanism for increased consistency and transparency where } \\
\text { pledges from individual countries could be better monitored and } \\
\text { controlled. }\end{array}$} \\
\hline Climate action & \\
\hline Life below water & \\
\hline Life on land & \\
\hline $\begin{array}{l}\text { Peace justice and strong } \\
\text { institutions }\end{array}$ & $\begin{array}{l}\text { These SDGs can be strengthened by blockchain where the } \\
\text { integrity of institutions and their directions can be absorbed } \\
\text { within blockchain solutions. The benefit of this is an engendering } \\
\text { of trust by affected parties and impacted citizens due to the } \\
\text { immutability and disintermediation aspects of blockchain. These } \\
\text { aspects could reinforce faith in government institutions and } \\
\text { directly impact peace and justice within communities. }\end{array}$ \\
\hline Partnerships for the goals & $\begin{array}{l}\text { By utilising the smart contract elements of blockchain, any } \\
\text { agreements in the determination of the SDGs between all } \\
\text { parties can be managed effectively. All incentives and } \\
\text { partnerships developed between countries and organisations in } \\
\text { the achievement of the SDGs can be automatically triggered on } \\
\text { fulfilment via the blockchain. }\end{array}$ \\
\hline
\end{tabular}

The alignment of blockchain technology and the UN SDGs highlights the many benefits that could materialise on widespread adoption. This would require significant investment together with collaboration at an international level to effect governance, standards and security. The migration toward blockchain could be led by developing economies as the barriers to adoption are likely to be reduced and the social and economic drivers engender greater impetus for change (Thiruchelvam et al. 2018).

\subsection{Innovation framework and research propositions}

Blockchain has the potential to act as a disruptor of change within a number of industrial and cultural contexts. The attributes of the technology lend themselves to potentially solving a number of global issues where traditional models require significant oversight and third party validation to assure integrity and fulfilment. However, although the potential for blockchain is clear as evidenced within many aspects of the literature, the relative immaturity of the technology and lack of momentum for commercial applications, could act as a barrier to implementation. Organisations looking to explore and potentially develop blockchain solutions face the dilemma of identifying tangible benefits to the business whilst being pragmatic on the Return On Investment (ROI) and subsequent risk to the organisation. This study offers relevant contribution to this problem via the presentation of a framework that seeks to guide both researchers and practitioners in the decision loop for the implementation or procurement of blockchain based technologies. 
The study by Rogers (2003) presents a Model of the Innovation Decision Process (MIDP) that addresses the uncertainty surrounding innovation by establishing a set of sequential stages of decision making. The model outlined within Rogers (2010) presented five stages that document the innovation decision process as follows:

1. Knowledge - where a decision maker is exposed to the existence of an innovation.

2. Persuasion - a favourable or unfavourable view is formed on the innovation.

3. Decision - where the innovation is rejected or accepted.

4. Implementation - the new idea is developed or procured.

5. Confirmation - does the innovation deliver what was expected?

These steps are positioned as framing the journey from idea to implementation as well as the reflection and feedback loop via the confirmation step. By applying the key elements of the Rogers (2003) innovation model, we propose a framework that can guide the progression toward the development and procurement of blockchain solutions.

The Blockchain Innovation Framework (BIF) is presented in figure 4 where the key elements of the Rogers (2003) model are integrated to each of the stages. Organisations that are reviewing the potential for blockchain applications can use the framework to ensure transparency and to follow a formal process where key questions need to be answered at each stage. By following the underlying processes within the framework, key decision points are established where organisations need to reflect on the decisions made at each step. The framework seeks to establish if blockchain is the correct option and whether some of the limitations of the technology have been fully understood and applied. Furthermore, the framework retains a focus on the overall benefits to the organisation from the technology and the criticality of the confirmation step where a process of continuous improvement is advocated. It is envisaged that the framework would form part of an overall strategic decision making process and that organisations would seek to identify many of the cultural and technological barriers that may hinder adoption of the technology. These factors are critical as technological innovation alone cannot deliver success unless many other factors relating to change and its impact on citizens and wider stakeholders are understood (Dwivedi et al. 2017 Dwivedi et al. 2017ab; Kapoor et al. 2014ab; Rana et al. 2016;2017).

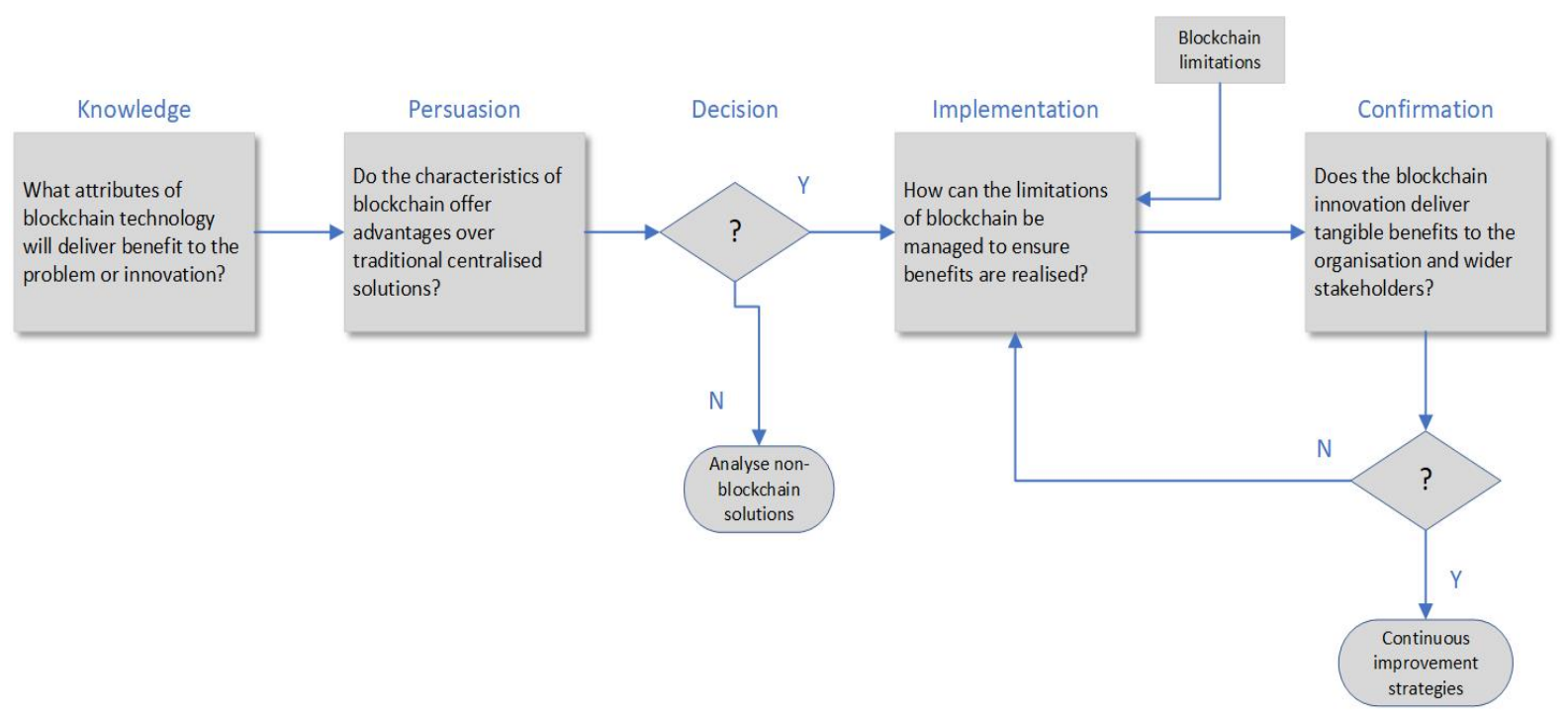

Figure 4: Blockchain Innovation Framework (BIF) (Source: Adapted from Rogers 2003) 
In order to guide future research in this area, a number of research propositions are set out in Table 4. Each of the propositions align with one or more of the elements within the framework. Each of the propositions were developed from the literature review and assessment of the benefits and limitations in the context of the Indian public sector cases and wider use cases. The propositions are not industry or use case specific but may have greater relevance in certain cultural and economic contexts. The propositions are not directly linked to the UN SDGs but one or more may be realised if specific SDGs are fulfilled.

Table 4: Research propositions

\begin{tabular}{|c|c|c|}
\hline Independent Variable & Dependent Variable & Proposition \\
\hline $\begin{array}{l}\text { Perception of benefits } \\
\text { from blockchain. }\end{array}$ & $\begin{array}{l}\text { Increased investment in } \\
\text { blockchain technology. }\end{array}$ & $\begin{array}{l}\text { Benefit expectation via one or more } \\
\text { attributes of blockchain technology will } \\
\text { positively drive investment in commercial } \\
\text { applications. }\end{array}$ \\
\hline $\begin{array}{l}\text { International } \\
\text { standardisation of } \\
\text { blockchain. }\end{array}$ & $\begin{array}{l}\text { Increased levels of } \\
\text { commercial blockchain } \\
\text { applications. }\end{array}$ & $\begin{array}{l}\text { International standardisation and } \\
\text { governance will have a positive effect in } \\
\text { engendering an acceleration in } \\
\text { commercial blockchain applications. }\end{array}$ \\
\hline $\begin{array}{l}\text { Perception of benefits } \\
\text { from blockchain. }\end{array}$ & $\begin{array}{l}\text { Increased investment in } \\
\text { blockchain technology. }\end{array}$ & $\begin{array}{l}\text { Positive cultural and social influences will } \\
\text { drive the transition toward blockchain } \\
\text { applications. }\end{array}$ \\
\hline Benefit expectation. & $\begin{array}{l}\text { Lowered resistance and } \\
\text { increased levels of } \\
\text { adoption. }\end{array}$ & $\begin{array}{l}\text { Expectation of benefits from citizens will } \\
\text { address resistance to using blockchain } \\
\text { applications. }\end{array}$ \\
\hline $\begin{array}{l}\text { Investment in } \\
\text { blockchain technology } \\
\text { within developing } \\
\text { countries. }\end{array}$ & $\begin{array}{l}\text { Increased blockchain } \\
\text { applications within } \\
\text { developing economies. }\end{array}$ & $\begin{array}{l}\text { Developing countries will forge ahead } \\
\text { with blockchain to solve fundamental } \\
\text { issues that directly impact citizens lives } \\
\text { and welfare. }\end{array}$ \\
\hline $\begin{array}{l}\text { Overcoming inherent } \\
\text { limitations of } \\
\text { blockchain. }\end{array}$ & $\begin{array}{l}\text { High impact use cases } \\
\text { migrate to blockchain } \\
\text { technology. }\end{array}$ & $\begin{array}{l}\text { Current limitations inherent within } \\
\text { blockchain technology will be addressed } \\
\text { for high impact use cases that offer the } \\
\text { greatest benefits. }\end{array}$ \\
\hline $\begin{array}{l}\text { Investment in } \\
\text { information security } \\
\text { alongside } \\
\text { developments in the } \\
\text { technology. }\end{array}$ & $\begin{array}{l}\text { Increased levels of } \\
\text { blockchain based } \\
\text { information security. }\end{array}$ & $\begin{array}{l}\text { Trust in blockchain technology will be } \\
\text { positively influenced by the development } \\
\text { and adaptation of new Information } \\
\text { security processes and standards. }\end{array}$ \\
\hline $\begin{array}{l}\text { Perceptions of } \\
\text { negativity }\end{array}$ & $\begin{array}{l}\text { Reduction in trust for non- } \\
\text { blockchain applications }\end{array}$ & $\begin{array}{l}\text { Negativity will increase for traditional } \\
\text { non-blockchain architectures due to } \\
\text { lower levels of trust. }\end{array}$ \\
\hline
\end{tabular}

Proposition 1: Benefit expectation via one or more attributes of blockchain technology will positively drive investment in commercial applications

Benefit expectation relates to the quantifiable benefits that are expected to be realised on implementation of a blockchain solution. This proposition (\#1) relates to the Confirmation stage of the framework where an assessment is made as to whether the organisation has accrued the envisaged 
benefits over systems using traditional infrastructures. Organisations are likely to invest in blockchain based projects where the inherent attributes of the technology can address significant gaps within existing traditional solutions.

Proposition 2: International standardisation and governance will have a positive effect in engendering an acceleration in commercial blockchain applications.

Agreement on international governance processes and standardisation of the technology will enable organisations to better align with strategic blockchain applications. This is critical for supply chain and logistics use cases where goods are shipped, tracked and delivered across international boundaries in adherence to smart blockchain contracts. The supply and logistics use cases are frequently cited as blockchain applications yielding significant potential benefits for each of the stakeholders (Levine 2017; Queiroz and Wamba 2019; Staples et al. 2017). This proposition (\#2) aligns with the Implementation stage and highlights the momentum potential for the technology if organisations can develop blockchain solutions against an agreed set of standards and protocols.

Proposition 3: Positive cultural and social influences will drive the transition toward blockchain applications.

The momentum toward blockchain will be greatest where social and cultural aspects can influence the development and adoption of blockchain solutions. This is likely to occur within specific use cases where the implementation of blockchain solutions provides disruptive change to the lives of citizens and organisations involved in the value chain. This proposition (\#3) is associated with the Persuasion and Decision stages of the framework.

Proposition 4: Expectation of benefits from citizens will address resistance to using blockchain applications.

Although there exists a degree of awareness for blockchain amongst the wider population, few will have had any direct interaction with blockchain based applications. Consequently, it is reasonable to expect a certain level of resistance due to the perceived risks or limitations from blockchain (Drescher 2017). However, where applications utilise blockchain attributes such as: improved levels of trust, immutability and non-repudiation as core elements of their functionality, the benefits of blockchain applications will override any initial resistance. This proposition (\#4) lies within the Implementation stage of the framework as users and organisations alike assess the benefits vs limitations of the technology.

Proposition 5: Developing countries will forge ahead with blockchain to solve fundamental issues that directly impact citizens' lives and welfare.

The benefits of using blockchain within developing economies will provide the impetus for investment in the technology. The issues relating to BPL Indian migrants and their inability to claim their food rations out of state (WFP 2014), highlights a situation where these factors could engender a drive for political and institutional support for the technology within developing economies. This proposition (\#5) aligns with the Knowledge and Persuasion stages of the framework.

Proposition 6: Current limitations inherent within blockchain technology will be addressed for high impact use cases that offer the greatest benefits.

Blockchain in its current form exhibits a number of limitations that could prohibit widespread use of the technology. Studies have highlighted blockchains limitations in the context of: lack of privacy, high cost, security model limitations, lack of flexibility and latency for larger blockchains (Axios 2018; 
Böhme et al. 2017; Coyne \& McMickle 2017; Drescher 2017; Forester 2018). However, within specific use cases where the greatest value can be generated - smart contracts, supply chain and logistics, these limitations will be addressed to ensure adequate benefits can be realised. This proposition (\#6) is associated with the Implementation stage of the framework.

Proposition 7: Trust in blockchain technology will be positively influenced by the development and adaptation of new Information security processes and standards.

One of the stated benefits of blockchain in its current form is the transparency of transactions where each are added to every node in the network thereby, ensuring the overall integrity in the blockchain. This specific attribute is also a potential limitation in that this transparency is likely to not adhere to current information security and GDPR regulations. These issues shave been highlighted within the existing literature (Kshetri 2017; Kypriotaki et al. 2015; Levine 2017) indicating that governance and subsequent information security protocols would need revision to adhere to GDPR and related regulations. The formalising of these processes and standards specific to blockchain technology, will positively impact trust in blockchain applications. This proposition (\#7) aligns with the Implementation stage of the framework.

Proposition 8: Negativity will increase for traditional non-blockchain architectures due to lower levels of trust.

As momentum increases for the development of blockchain based applications, the limitations of traditional architectures for specific use cases are likely to be a barrier for continued adoption for nonblockchain applications. This scenario could engender an acceleration toward blockchain technology as the perceived benefits of this approach are seen to surpass those of centralised architectures. This proposition (\#8) can be associated with the Persuasion stage of the framework.

\subsection{Limitations and future research}

The study is perhaps limited by the focus on the IS/IM related perspective. However, we have articulated this position as the specific gap in the literature that has not been addressed within previous studies. We advocate future research within a number of specific areas that in our view could yield the greatest contribution to literature:

- In depth analysis of the specific use cases and scenarios where blockchain has the potential to offer significant benefits. This study discussed the migrant issues within India as an example. Future research could analyse the potential for blockchain within this context or other similar areas.

- This study discusses the lack of commercially available blockchain solutions. This current position is likely to exist for a number of technical and commercial reasons. Future research could provide empirical evidence of the current debates within industry and academia on the barriers to implementation and the likely specific use case trajectory.

- Assuming a scenario where blockchain technology becomes a core element of organisations future strategic plans, what is the likely impact on traditional architecture based systems and how do organisations make the key decisions needed that will deliver benefits? Future research could analyse the key components of this transition and offer insight to the roadmap that organisations will need to travel as they traverse along the path toward blockchain applications. 


\section{Conclusions}

Blockchain has emerged as one of the most promising and potentially transformative technologies of recent times. Studies have posited its ability to extensively disrupt established business processes and engender trust and integrity whilst at the same time offering disintermediation and immutability. These aspects have tremendous ramifications to organisations considering the technology. Further studies argue that this is the territory of blinkered and perhaps misguided visionaries who fail to look through the lens of pragmatism and realism, the requirement to reinvent entire industries, establish new cultural norms and re-engineer new business processes. The challenge for blockchain is to maintain the integrity of its potential to transform industry whilst addressing the many limitations of the technology.

Notwithstanding the current limitations of blockchain technology, there exists tremendous potential for a growing number of use cases where the attributes of blockchain can be used to great effect. This study uses the cases of the migrant population and poorly paid farmers in India as example use cases where blockchain technology could offer real change and significant benefits for farmers and BPL Indian citizens. Other examples within the supply chain and logistics industries are also discussed that could greatly benefit from blockchain solutions.

Blockchain is still a relatively immature concept and studies have highlighted that beyond feasibility few real world applications exist, posing a dilemma to organisations looking at the technology to understand the impact on their existing processes. This study supports aspects of the literature such as the study by Beck et al. (2017) that advocates a positive yet pragmatic focussed perspective on blockchain. This entails further research on mitigating the risks of blockchain, its unintended consequences, impact on established markets and cultural ramifications as well as benefits to industry. We present this study as a thorough review of the blockchain literature that attempts to offer an IS/IM and business benefit focussed perspective. This study develops and discusses a number of the key themes relating to blockchain and highlights the many benefits and limitations of the technology. By adapting the Rogers (2003) MIDP model, this study presents a blockchain innovation framework as a mechanism for guiding both research and practice in the progression toward the development and procurement of blockchain solutions.

\section{References}

Alabi, K. (2017). Digital blockchain networks appear to be following metcalfe's law. Electronic Commerce Research and Applications, 24, 23-29.

Aste, T., Tasca, P., \& Di Matteo, T. (2017). Blockchain technologies: The foreseeable impact on society and industry. Computer, 50(9), 18-28.

Avital, M. (2018). Peer review: Toward a blockchain-enabled market-based ecosystem. Communications of the Association for Information Systems, 42(1), 646-653.

Axios (2018). Corporate America's blockchain and bitcoin fever is over.

https://www.axios.com/corporate-america-blockchain-bitcoin-fervor-over-fb13bc5c-81fd-4c12-

8a7b-07ad107817ca.html. (Accessed January 2019)

Bailis, P., Narayanan, A., Miller, A., \& Han, S. (2017). Research for practice: cryptocurrencies, blockchains, and smart contracts; hardware for deep learning. Communications of the ACM, 60(5), 4851. 
Barnett, J., \& Treleaven, P. (2018). Algorithmic dispute resolution-the automation of professional dispute resolution using Al and blockchain technologies. Computer Journal, 61(3), 399-408.

Beck, R., Czepluch, J. S., Lollike, N., \& Malone, S. (2016, May). Blockchain-the Gateway to Trust-Free Cryptographic Transactions. In ECIS (153).

Beck, R., Avital, M., Rossi, M., \& Thatcher, J. B. (2017). Blockchain technology in business and information systems research. Bus. Information Systems Engineering (59), 381-384

Bitcoin (2019). How Does Bitcoin Work. https://bitcoin.org/en/how-it-works (Accessed January 2019)

Böhme, R., Christin, N., Edelman, B. and Moore, T., 2015. Bitcoin: Economics, technology, and governance. Journal of Economic Perspectives, 29(2), 213-38.

Carrenõ, R., Aguilar, V., Pacheco, D., Acevedo, M. A., Yu, W., \& Acevedo, M. E. (2018). An loT expert system shell in block-chain technology with ELM as inference engine. International Journal of Information Technology and Decision Making. 1-18.

Coyne, J. G., \& McMickle, P. L. (2017). Can blockchains serve an accounting purpose? Journal of Emerging Technologies in Accounting, 14(2), 101-111

Dai, J., \& Vasarhelyi, M. A. (2017). Toward blockchain-based accounting and assurance. Journal of Information Systems, 31(3), 5-21.

Deloitte.com (2019). Blockchain technology in India.

https://www2.deloitte.com/content/dam/Deloitte/in/Documents/strategy/in-strategy-innovationblockchain-technology-india-opportunities-challenges-noexp.pdf. (Accessed February 2019).

Dobrovnik, M., Herold, D., Fürst, E. and Kummer, S. (2018). Blockchain for and in Logistics: What to Adopt and Where to Start. Logistics, 2(3), p.18.

Dorri, A., Kanhere, S.S., Jurdak, R. and Gauravaram, P., 2017, March. Blockchain for loT security and privacy: The case study of a smart home. In Pervasive Computing and Communications Workshops (PerCom Workshops), 2017 IEEE International Conference on (pp. 618-623). IEEE.

Drescher, D. Blockchain Basics: A Non-technical Introduction in 25 Steps, 1st Edn. Apress, Frankfurt am Main (2017).

Duan, Y., Edwards, J. S., \& Dwivedi, Y. K. (2019). Artificial intelligence for decision making in the era of Big Data-evolution, challenges and research agenda. International Journal of Information Management, 48, 63-71.

Dwivedi, Y. K., Rana, N. P., Janssen, M., Lal, B., Williams, M. D., \& Clement, M. (2017a). An empirical validation of a unified model of electronic government adoption (UMEGA). Government Information Quarterly, 34(2), 211-230.

Dwivedi, Y. K., Rana, N. P., Jeyaraj, A., Clement, M., \& Williams, M. D. (2017b). Re-examining the unified theory of acceptance and use of technology (UTAUT): Towards a revised theoretical model. Information Systems Frontiers, 1-16. Dol: https://doi.org/10.1007/s10796-017-9774-y

Dwivedi, Y. K., Wastell, D., Laumer, S., Henriksen, H. Z., Myers, M. D., Bunker, D., ... \& Srivastava, S. C. (2015). Research on information systems failures and successes: Status update and future directions. Information Systems Frontiers, 17(1), 143-157. 
Dwivedi, Y.K., Henriksen, H.Z., Wastell, D., \& De', R. (eds.). (2013). Grand Successes and Failures in IT: Public and Private Sectors. Springer.

Dwivedi, Y. K., Weerakkody, V., \& Janssen, M. (2012). Moving towards maturity: challenges to successful e-government implementation and diffusion. ACM SIGMIS Database: the DATABASE for Advances in Information Systems, 42(4), 11-22.

Economic Times (2019), ICICl, Kotak, Axis among 11 to launch blockchain-linked funding for SMEs, https://economictimes.indiatimes.com/markets/stocks/news/icici-kotak-axis-among-11-tolaunch-blockchain-linked-funding-for-smes/articleshow/67718025.cms. (Accessed January 2019)

Eyal, I., \& Sirer, E. G. (2018). Majority is not enough: Bitcoin mining is vulnerable. Communications of the ACM, 61(7), 95-102.

Fengi, L., Zhang, H., Lou, L., \& Chen, Y. (2018). A blockchain-based collocation storage architecture for data security process platform of WSN. Paper presented at the Proceedings of the 2018 IEEE 22nd International Conference on Computer Supported Cooperative Work in Design, CSCWD 2018, 39-44.

Forester 2018: The Blockchain Revolution Will Have To Wait A Little Longer.

https://go.forrester.com/blogs/predictions-2018-the-blockchain-revolution-will-have-to-wait-alittle-longer/. (Accessed December 2018).

Fosso Wamba, S., Kamdjoug, K., Robert, J., Bawack, R., \& G Keogh, J. (2018). Bitcoin, Blockchain, and FinTech: A Systematic Review and Case Studies in the Supply Chain. Production Planning and Control, Forthcoming.

Fosso Wamba, S. (2018). Continuance Intention in Blockchain-Enabled Supply Chain Applications: Modelling the Moderating Effect of Supply Chain Stakeholders Trust. In European, Mediterranean, and Middle Eastern Conference on Information Systems (pp. 38-43). Springer, Cham.

Francisco, K., \& Swanson, D. (2018). The supply chain has no clothes: technology adoption of blockchain for supply chain transparency. Logistics, 2(1), 2.

Gomber, P., Kauffman, R. J., Parker, C., \& Weber, B. W. (2018). On the fintech revolution: Interpreting the forces of innovation, disruption, and transformation in financial services. Journal of Management Information Systems, 35(1), 220-265.

Grover, P., Kar, A. K., \& llavarasan, P. V. (2018). Blockchain for businesses: A systematic literature review. In Conference on e-Business, e-Services and e-Society, 325-336. Springer, Cham.

Guo, Y. and Liang, C., 2016. Blockchain application and outlook in the banking industry. Financial Innovation, 2(1), 24.

Hawlitschek, F., Notheisen, B., \& Teubner, T. (2018). The limits of trust-free systems: A literature review on blockchain technology and trust in the sharing economy. Electronic Commerce Research and Applications, 29, 50-63.

Holub, M., \& Johnson, J. (2018). Bitcoin research across disciplines. Information Society, 34(2), 114126.

Hughes, D. L., Rana, N. P., \& Dwivedi, Y. K. (2019). Elucidation of IS project success factors: an interpretive structural modelling approach. Annals of Operations Research, 1-32. Dol: https://doi.org/10.1007/s10479-019-03146-w 
Hughes, D. L., Dwivedi, Y. K., \& Rana, N. P. (2017). Mapping IS failure factors on PRINCE2 ${ }^{\circledR}$ stages: An application of interpretive ranking process (IRP). Production Planning \& Control, 28(9), 776-790.

Hughes, D. L., Dwivedi, Y. K., Rana, N. P., \& Simintiras, A. C. (2016). Information systems project failureanalysis of causal links using interpretive structural modelling. Production Planning \& Control, 27(16), 1313-1333.

Hughes, D. L., Dwivedi, Y. K., Simintiras, A. C., \& Rana, N. P. (2015). Success and failure of IS/IT projects: A state of the art analysis and future directions. Springer.

Iansiti, M. and Lakhani, K.R. (2017). The truth about blockchain. Harvard Business Review, 95(1), pp.118-127.

IBD (Investors Business Daily). (2018). The Blockchain Technology Revolution Is About To Remake The Stock Market. https://www.investors.com/news/technology/blockchain-technology-blockchainstock-market-revolution/. (Accessed December 2018).

Independent (2018). Facebook cryptocurrency plans boosted by blockchain hiring spree. https://www.independent.co.uk/topic/bitcoin. (Accessed December 2018).

India.gov (2019). National Food Security Act 2013. https://www.india.gov.in/national-food-securityact-2013. (Accessed January 2019).

Ismagilova, E., Hughes, L., Dwivedi, Y.K. and Raman, K.R. (2019). Smart cities: Advances in researchAn information systems perspective. International Journal of Information Management, 47, 88-100.

Kapoor, K. K., Tamilmani, K., Rana, N. P., Patil, P., Dwivedi, Y. K., \& Nerur, S. (2018). Advances in social media research: past, present and future. Information Systems Frontiers, 1-28.

Kapoor, K. K., Dwivedi, Y. K., \& Williams, M. D. (2014a). Rogers' innovation adoption attributes: A systematic review and synthesis of existing research. Information Systems Management, 31(1), 7491.

Kapoor, K., Dwivedi, Y.K, \& Williams, M.D. (2014b). Innovation adoption attributes: a review and synthesis of research findings. European Journal of Innovation Management, 17(3), 327-348.

Kshetri, N. (2018). 1 blockchain's roles in meeting key supply chain management objectives. International Journal of Information Management, 39, 80-89.

Kshetri, N. (2017). Potential roles of blockchain in fighting poverty and reducing financial exclusion in the global south. Journal of Global Information Technology Management, 20(4), 201-204.

Kuo, T.T., Kim, H.E. and Ohno-Machado, L. (2017). Blockchain distributed ledger technologies for biomedical and health care applications. Journal of the American Medical Informatics Association, 24(6), pp.1211-1220.

Tamilmani, K., Rana, N. P., Prakasam, N., \& Dwivedi, Y. K. (2019). The battle of Brain vs. Heart: A literature review and meta-analysis of "hedonic motivation" use in UTAUT2. International Journal of Information Management, 46, 222-235.

Kypriotaki, K. N., Zamani, E. D., \& Giaglis, G. M. (2015). From bitcoin to decentralized autonomous corporations: Extending the application scope of decentralized peer-to-peer networks and blockchains. Paper presented at the ICEIS 2015 - 17th International Conference on Enterprise Information Systems, Proceedings, 3, 284-290. 
Lacity, M. C. (2018). Addressing key challenges to making enterprise blockchain applications a reality. MIS Quarterly Executive, 17(3), 201-222.

Levine, M. (2017). Cargo blockchains and Deutsche bank. Retrieved from

https://www.bloomberg.com/view/articles/2017-03-06/cargo-blockchains-and-deutsche-bank. (Accessed January 2019).

Li, X., \& Wang, C. A. (2017). The technology and economic determinants of cryptocurrency exchange rates: The case of bitcoin. Decision Support Systems, 95, 49-60.

Li, Z., Wang, W. M., Liu, G., Liu, L., He, J., \& Huang, G. Q. (2018). Toward open manufacturing a crossenterprises knowledge and services exchange framework based on blockchain and edge computing. Industrial Management and Data Systems, 118(1), 303-320.

Loebbecke, C., \& Picot, A. (2015). Reflections on societal and business model transformation arising from digitization and big data analytics: A research agenda. The Journal of Strategic Information Systems, 24(3), 149-157.

Lynn, T., Rosati, P., \& Fox, G. (2018). Legitimizing\# Blockchain: An empirical analysis of firm level social media messaging on Twitter. In 26th European Conference on Information Systems (ECIS 2018).

Mendling, J., Weber, I., Aalst, W.V.D., Brocke, J.V., Cabanillas, C., Daniel, F., Debois, S., Ciccio, C.D., Dumas, M., Dustdar, S. and Gal, A. (2018). Blockchains for business process management-challenges and opportunities. ACM Transactions on Management Information Systems (TMIS), 9(1), p.4.

Michelman, P. (2017). Seeing Beyond the Blockchain Hype. MIT Sloan Management Review, 58(4), 17.

Migration Policy Institute (2014). Internal Labour Migration in India Raises Integration Challenges for Migrants. https://www.migrationpolicy.org/article/internal-labor-migration-india-raises-integrationchallenges-migrants. (Accessed January 2019).

Nakamoto, S. (2008). Bitcoin: A peer-to-peer electronic cash system. https://bitcoin.org/bitcoin.pdf 2008. (Accessed December 2018).

Niti.gov (2019). Doubling Farmers Income. Rationale, Strategy, Prospects and Action Plan. http://niti.gov.in/writereaddata/files/document_publication/DOUBLING\%20FARMERS\%20INCOME.p df. (Accessed January 2019).

ØInes, S., Ubacht, J., \& Janssen, M. (2017). Blockchain in government: Benefits and implications of distributed ledger technology for information sharing. Government Information Quarterly, 34(3), 355364.

Pappas, I. O., P. Mikalef, M. N. Giannakos, J. Krogstie and G. Lekakos (2018). "Big data and business analytics ecosystems: paving the way towards digital transformation and sustainable societies." Information Systems and e-Business Management 16(3): 479-491.

Pappas, I. O., L. Jaccheri, P. Mikalef and M. N. Giannakos (2017). Social Innovation and Social Entrepreneurship through Big Data: Developing a Research Agenda. 11th Mediterranean Conference on Information Systems (MCIS). Genoa, Italy. 
Pazaitis, A., De Filippi, P. and Kostakis, V. (2017). Blockchain and value systems in the sharing economy: The illustrative case of Backfeed. Technological Forecasting and Social Change, 125, 105-115.

Peters, G.W. and Panayi, E. (2016). Understanding modern banking ledgers through blockchain technologies: Future of transaction processing and smart contracts on the internet of money. In Banking Beyond Banks and Money (239-278). Springer, Cham.

Planning Commission. (2015). Performance Evaluation of Targeted Public Distribution System (TPDS) (No. id: 6773).

Queiroz, M.M. and Wamba, S.F., 2019. Blockchain adoption challenges in supply chain: An empirical investigation of the main drivers in India and the USA. International Journal of Information Management, 46, 70-82.

Rabah, K. (2017). Overview of Blockchain as the Engine of the 4th Industrial Revolution. Mara Research Journal of Business \& Management 1(1), 125-135.

Rana NP, Dwivedi YK, Lal B, Williams MD \& Clement M (2017). Citizens' adoption of an electronic government system: towards a unified view. Information Systems Frontiers, 19(3), 549-568.

Rana NP, Dwivedi YK, Williams MD \& Weerakkody V (2016). Adoption of online public grievance redressal system in India: Toward developing a unified view. Computers in Human Behavior, 59, 265282.

Rimba, P., Tran, A. B., Weber, I., Staples, M., Ponomarev, A., \& Xu, X. (2018). Quantifying the cost of distrust: Comparing blockchain and cloud services for business process execution. Information Systems Frontiers, 1-19.

Rogers, E.M., (2003). Diffusion of innovations. Simon and Schuster, New York.

Seebacher, S. and Schüritz, R. (2017). Blockchain technology as an enabler of service systems: A structured literature review. In International Conference on Exploring Services Science, 12-23. Springer, Cham.

SimplyFl.tech (2019). Blockchain Products. https://simplyfi.tech/ (Accessed February 2019).

Staples, M., Chen, S., Falamaki, S., Ponomarev, A., Rimba, P., Tran, A. B., \& Zhu, L. (2017). Risks and opportunities for systems using blockchain and smart contracts. Data61 (CSIRO).

Tan, A. W. K., Zhao, Y., \& Halliday, T. (2018). A blockchain model for less container load operations in china. International Journal of Information Systems and Supply Chain Management, 11(2), 39-53.

Tang, H., Shi, Y., \& Dong, P. (2019). Public blockchain evaluation using entropy and TOPSIS. Expert Systems with Applications, 117, 204-210.

Tapscott, D. and Tapscott, A. (2017). How blockchain will change organizations. MIT Sloan Management Review, 58(2), 10.

Tasca, P., Hayes, A. and Liu, S. (2018). The evolution of the bitcoin economy: extracting and analyzing the network of payment relationships. The Journal of Risk Finance, 19(2), 94-126.

Thiruchelvam, V., Mughisha, A. S., Shahpasand, M., \& Bamiah, M. (2018). Blockchain-based Technology in the Coffee Supply Chain Trade: Case of Burundi Coffee. Journal of Telecommunication, Electronic and Computer Engineering (JTEC), 10(3-2), 121-125. 
Times of India. (2018). India's food grain production touched new highs in 2017-18. https://timesofindia.indiatimes.com/business/india-business/indias-foodgrain-production-touchednew-high-in-2017-18/articleshow/65583069.cms. (Accessed February 2019).

Weber, I., Xu, X., Riveret, R., Governatori, G., Ponomarev, A., \& Mendling, J. (2016). Untrusted business process monitoring and execution using blockchain. In International Conference on Business Process Management (pp. 329-347). Springer, Cham.

WFP (World Food Programme). (2014). Targeted Public Distribution System: Best Practice Solutions. https://publications.wfp.org/en/annual-report/2014/. (Accessed February 2019).

White, G.R. (2017). Future applications of blockchain in business and management: A Delphi study. Strategic Change, 26(5), 439-451

Wüst, K. and Gervais, A., 2018, June. Do you need a Blockchain?. In 2018 Crypto Valley Conference on Blockchain Technology (CVCBT) 45-54. IEEE.

Ying, W., Jia, S., \& Du, W. (2018). Digital enablement of blockchain: Evidence from HNA group. International Journal of Information Management, 39, 1-4.

Yli-Huumo, J., Ko, D., Choi, S., Park, S. and Smolander, K., 2016. Where is current research on blockchain technology? - a systematic review. PloS one, 11(10).

Zalan, T. (2018). Born global on blockchain. Review of International Business and Strategy, 28(1), 1934.

Zamani, E. D., \& Giaglis, G. M. (2018). With a little help from the miners: Distributed ledger technology and market disintermediation. Industrial Management and Data Systems, 118(3), 637-652. 